\title{
EL MECENAZGO DE LOS MARQUESES DE MEJORADA EN LA IGLESIA Y CAPILLA DE SU VILLA. SU ALTAR-BALDAQUINO Y SUS ESCULTURAS DE MÁRMOL, DOCUMENTADOS *
}

\author{
POR \\ MARGARITA ESTELLA \\ Departamento de Historia del Arte «Diego Velázquez»
}

The Marqueses de Mejorada Patronage in the $17^{\text {th }}$ century: unpublished documents about the $=$ Altar-Baldaquine and the marbre sculptures of the Capilla de San Fausto (Mejorada del Campo - Madrid).

La muerte de Felipe IV marca el inicio del tercer tercio del siglo XVII, de tristes connotaciones para el poderoso Imperio español. Las artes que habían gozado de especial predilección del monarca, reflejan en muchos aspectos estos años de la decadencia política de España.

Como Urrea puntualiza en la introducción a su claro estudio sobre el escultor Pereira ${ }^{1}$, aunque la escuela madrileña de pintura continua el resplandor de los años de Velázquez, muerto en 1660, el campo de la escultura cortesana sólo presenta algunos nombres entre los que destaca el del artista citado. La arquitectura, según el cuidadoso estudio de Virginia To$\operatorname{var}^{2}$, da noticia de un hervor constructivo grande pero a cargo de maestros que no alcanzan la calidad de los que vivieron en la primera mitad de este siglo XVII, como Juan Gómez de Mora.

Los encargós reales, motor tantas veces de la vida artística, se interrumpen prácticamente y puede decirse que la estatua ecuestre de Felipe IV, objeto del interés de la diplomacia florentina, fue uno de los últimos de entidad. Obra firmada en 1640 por el italiano Tacca se instala el año de 1648 en el Jardín del Caballo del Buen Retiro. La Fuente de los Tritones se instala en el Jardín de la Isla de Aranjuez antes del año de 1659 cuando se describe por primera vez y aunque su calidad artística desmerece de otras fuentes del Jar-

\footnotetext{
* Al Profesor Renato Ruotolo, con mi agradecimiento.

1 Urrea, J.: «Introducción a la escultura barroca madrileña. Manuel Pereira». Boletín Seminario Estudios Arte y Arqueología, Valladolid (B.S.A.A.), 1977, pp. 253-268.

2 Tovar Martín, V.: Arquitectos madrileños de la segunda mitad del siglo XVII. Madrid, Instituto de Estudios Madrileños, 1975.
} 
dín, como la formada con los grupos del Algardi, fue celebrada con entusiasmo por cuantos visitantes la conocieron, por ejemplo Cósimo de Médicis que de nuevo se ocupa de ella el año de $1668^{3}$.

En realidad se emprenden algunas otras empresas artísticas de interés concebidas en su conjunto pero su destrucción sistemática o la injuria que padecieron en el transcurso de los años dificultaron el conocimiento exacto de su importancia, como puede decirse de la famosa Capilla de San Isidro en San Andrés, recientemente restaurada ${ }^{4}$. Entre éstas destacan las emprendidas por los Fernández del Campo, personajes que partir de los años de 1670 promocionaron las artes y de una de cuyas empresas se da nota en este estudio.

\section{LOS FERNÁNDEZ DEL CAMPO}

La biografía de Pedro Fernández del Campo, primer Marqués de Mejorada, muerto el 1680, y de su hijo Pedro Cayetano Fernández del Campo y de la Breña, muerto en 1721, han podido delinearse a grandes rasgos por medio de datos dispersos localizados en algunas publicaciones y en distintos Archivos.

Las noticias sobre su genealogía por García Carrafa y las que dieron el Duque de Maura, González Palencia y Escudero ${ }^{5}$ se han podido completar con la reunidas en los respectivos expedientes personales de sus Pruebas de Caballero de la Orden de Santiago, concedida a Pedro Fernández del Campo en 1649, la de la orden de Alcäntara disfrutada por su hijo Pedro Cayetano en fecha que no se ve bien en el ejemplar microfilmado del Archivo Histórico y que como se dirá no puẹde ser la de 1663 y la de la Orden de Calatrava de la que gozó desde 1659 Iñigo Fernández del Campo, hermano de Pedro y tío por la misma de Pedro Cayetano, cuya vida se entrelaza con las de éstos en todos sus aspectos ${ }^{6}$. A estas noticias documentales se ha añadido alguna otra localizada en los documentos utilizados en estos trabajos, a las que se aludirá en su caso.

3 Estella, M.: «El Círculo de los florentinos del entorno de los Leoni», Felipe II y las Artes. Congreso Internacional, Departamento de Historia del Arte, II (Moderno), Facultad de Geografía e Historia, Universidad Complutense de Madrid, 9 a 12 de diciembre de 1998 (Actas en prensa).- Idem. «Sobre las esculturas del Jardin de la Isla en Aranjuez», Velázquez y el Arte de su tiempo. V Jornadas de Arte. Departamento de Historia del Arte «Diego Velázquez», CSIC, 1991, pp. 333-348. - Idem. «La Venus del Jardin de la Isla en Aranjuez», Adán y Eva en Aranjuez. Investigaciones sobre la escultura en la Casa de Austria. Madrid, Museo del Prado, abril/mayo, 1992, pp. 71-88.

4 Macho Ortega, F.: «La Capilla de San Isidro en la parroquia de san Andrés de Madrid», Boletín de la Sociedad Española de Excursiones (BSEE), 1918, pp. 214-222.

5 García Carrafa, Alberto y Arturo: Enciclopedia Heráldica y Genealógica Hispano-Americana, T. 22 (Los Campo), p. 42.- Duque de Maura. Vida y Reinado de Carlos II. Madrid, 1942, 3 vols.— González Palencia, Ángel: Mayorazgos españoles. Madrid, 1929.- Idem. Diego de Saavedra y Fajardo. Su vida y sus obras. Madrid, Aguilar, 1940: al final de la obra, al comentar la continuación de la «Corona Gótica» por Núñez de Castro, dedicada precisamente a Pedro Fernández del Campo, Marqués de Mejorada.- Idem. «El Convento de los Agustinos Recoletos de Madrid», Revista de la Biblioteca, Archivos y Museos del Ayuntamiento de Madrid, XXIII, 1944, n. ${ }^{\circ}$ 50, pp. 419-431 - Escudero, J. A.: Los Secretarios de Estado y del Despacho (1474-1724). Madrid, Instituto de Estudios Administrativos, 1969, 4 vols.

6 Archivo Histórico Nacional (AHN): Pèdro Fernández del Campo. Órdenes Militares. Santiago. Pruebas de Caballero, 1649, Bilbao. Caja 560, Exp. 2890.- Pedro Cayetano Fernández del Campo. Órdenes Militares. Alcántara. Pruebas de Caballero. Legajo 509 (microfilmado, poco legible. En el índice se dice que las informaciones se realizan en 1663, lo que no es posible pues nació en 1656). - Íñigo Fernández del Campo. Órdenes Militares. Calatrava. Pruebas de Caballero, 1659. Legajo. 2130, Exp. 891. 


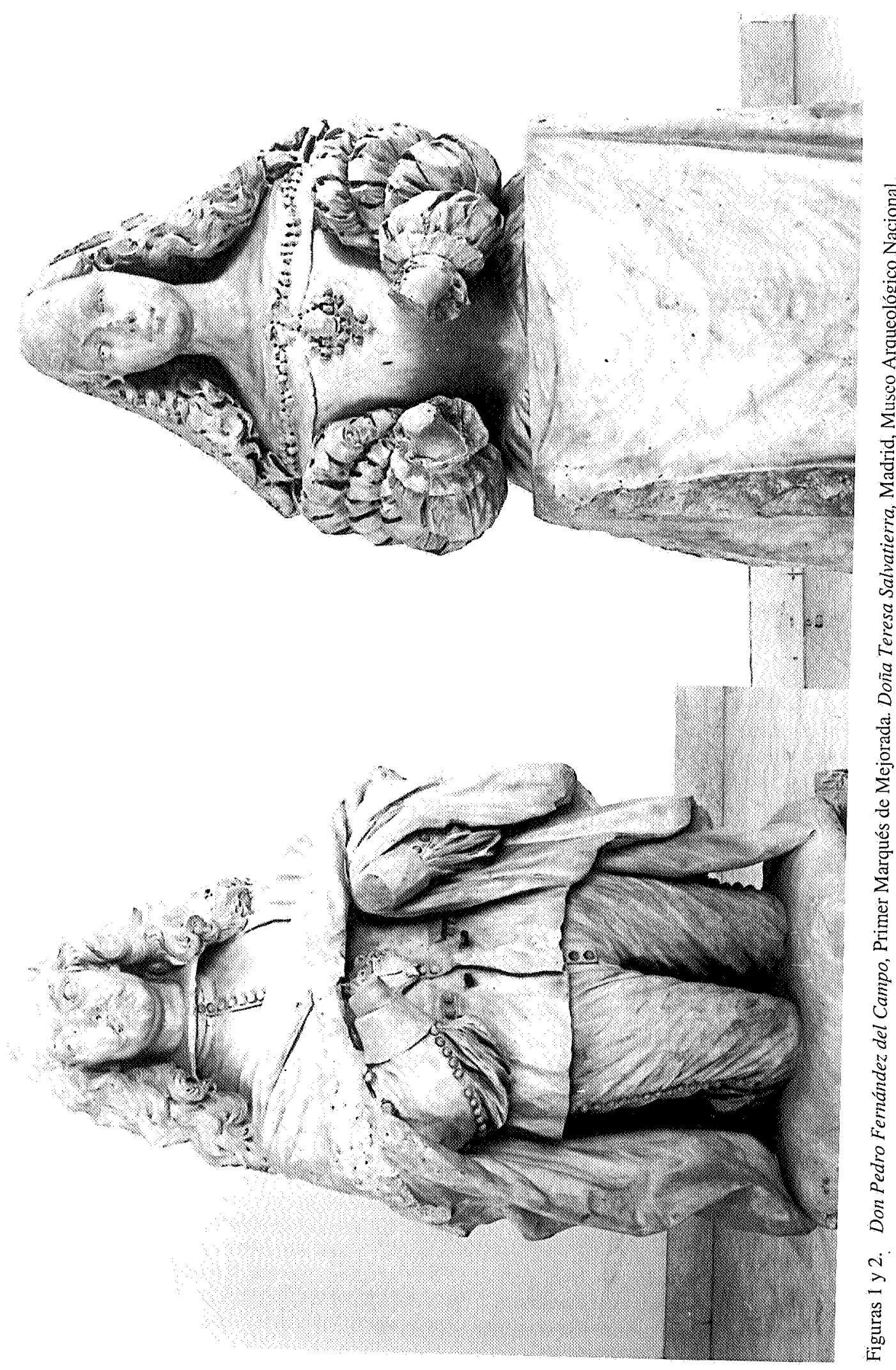


Con estos datos se ha podido trazar un esquema biográficos de los tres personajes. Hijosdalgos, no penitenciados por la Inquisición procedían los dos hermanos del Valle de Tudela donde tenían sus casas solariegas, que se visitan en las pruebas de Caballero de Iñigo. La información sobre los dos hermanos se obtiene en Bilbao y en el lugar de la Llana del Valle de Tudela en tanto que la relativa a Pedro Cayetano, ya nacido en Madrid, se lleva a cabo en tierras de Salamanca de donde procedía su madre Teresa Salvatierra y en Sallent, Jaca y otros lugares de esta comarca aragonesa donde se asentaron algunos otros de sus ascendientes maternos.

Pedro Fernández del Campo y Fernández Angulo, según González Palencia ${ }^{7}$, salió pronto de Madrid en 1632, a las campañas de Alemania y Flandes, llevando a cabo sus primeros ensayos de Gobierno en Cataluña y Milán. En su tercera estancia en Flandes aparece junto al aún Conde de Peñaranda en las conversaciones que precedieron a la Paz de Münster, como se lee en sus cartas del Archivo Histórico de Madrid ${ }^{8}$. Las capitulaciones matrimoniales con Teresa Salvatierra, oriunda de Salamanca, se realizan en el año de 1653 ante el escribano madrileño Eguiluz, matrimonio del que nace en 1656 Pedro Cayetano según Alvárez de Baena, que muere, la madre, en 1666 que se abre su testamento ante el Escribano citado a petición del esposo ${ }^{9}$. Sus cargos administrativos ante la Corte le llevan a la Secretaría de Despacho Universal en 1669 fecha en la que gozaba de la propiedad de las secretaría de Italia declarando en su toma de posesión que lleva al servicio del Rey más de 32 años, según Escudero ${ }^{10}$.

Su relación con Don Gaspar Bracamonte y Guzmán, Conde de Peñaranda, Virrey de Nápoles de 1658 a $1664^{11}$, se fortalece a través de su hermano Iñigo y quizás de la esposa de su hijo, Pedro Cayetanó, María Teresa Alvarado Bracamonte, cuya relación con el citado Virrey que sugiere su apellido no se ha podido establecer ${ }^{12}$.

Se le concede el título de Marqués de Mejorada en $1673^{13}$ a cuyo evento habría precedido la compra del Señorío de la Villa de Mejorada y del Patronato de la Capilla Mayor, Bóveda y Cripta de su Iglesia de lo que se hablará.

Por las mismas fechas decide su entierro en el Convento de Agustinos Recoletos de Madrid para lo que compra en 1671 el Patronato de su Capilla Mayor y al año siguiente el de su Bóveda donde como se dirá se inician las empresas artísticas familiares que continuará su hijo ${ }^{14}$.

7 González Palencia, cit. en nota 5.

8 AHN. Sección Estado, Libro 875, f. ${ }^{\circ} 24$ y Libro 879, f. 299.

9 Archivo Histórico de Protocolos de Madrid (APM). Protocolo n. ${ }^{\circ}$ 10066, Pérez Ortiz. Grueso protocolo que incluye la Testamentaría de Pedro Fernández del Campo, con la Tasación e Inventario de sus bienes. Comienza a su muerte en 1680, a petición de su hijo Pedro Cayetano Fernández del Campo, se tramita a partir de 1683 y finaliza en 1687. Incluye las Capitulaciones matrimoniales de Teresa Salvatierra con Pedro Fernández del Campo en 1653 y el Inventario de los bienes de aquélla, a su muerte en 1666. También transcribe, lógicamente, el Testamento de Pedro Fernández del Campo, dictado en 1679 y abierto a su muerte en 1680 - Álvarez Baena, J. A.: Hijos de Madrid, ilustres en santidad, ciencias y artes..., Madrid, 1973 (de la edición de 1789). Nació Pedro Cayetano en 1656, fecha de acuerdo a las Capitulaciones matrimoniales de sus padres en 1653 o sea que no pudo ser Caballero, en 1663. ¿Puede estar equivocada la fecha con la de 1683 ?

${ }^{10}$ Escudero, J. A., cit. en nota 5.

"Coniglio, G.: Il Viceré spagnoli di Napoli, Napoli, Fausto Fiorentina, 1967 (Collanea di cultura napoletana, 16): Gaspar de Bracamonte y Guzmán, Conde de Peñaranda, Virrey de Nápoles de 1658 a 1664.

${ }_{12}$ García Carrafa, cit. en nota 5.- En APM, Protocolo n. ${ }^{\circ}$ 13337, f. ${ }^{\circ}$ 408: Pedro Cayetano como marido y conjunta persona de la Sr. ${ }^{a}$ D. ${ }^{a}$ María Theresa de Alvarado y Bracamonte y Griñón, Marquesa de la Breña y de Mejorada, su legítima esposa. (En escritura de prorrogación del arrendamiento de los Estancos del tabaco de dicha Isla — Ciudad de San Cristóbal de La Laguna - en la Isla de Tenerife; en Protocolo n. ${ }^{\circ} 12693$. Munilla, F.: Sobre la familia de los Alvarado, no aclara nada.

${ }_{13}$ Es la fecha lógica pues toma posesión de la Villa en 1672.

14 Estella Marcos, M.: «Estatuas funerarias madrileñas del siglo XVII», BSAA, Valladolid, 1982, pp. 253-280: toda la documentación referente al Patronato de la Capilla Mayor de los Agustinos Recoletos de Madrid y a su entierro. 
También poseía en Madrid Casas Principales a San Martín pues no se cita en el Inventario de sus bienes la casa de las Siete Chimeneas que al parecer también poseyó algún tiempo ${ }^{15}$.

En 1673 recuerda que Felipe IV había aceptado la renuncia al cargo de Escribano de mandamiento de la Real Hacienda del Reino de Nápoles que su hermano Iñigo cede a su hijo Pedro Cayetano, sustituido por Nicolás Villani seguramente por compra del privilegio, y que debe ser el mismo al que se alude en 1721 cuando se dice que su hijo gozaba por cinco vidas del Oficio de Escribano Regio de Mandamiento del Consejo Colateral de la ciudad de Nápoles ${ }^{16}$.

Dicta testamento un año antes de su muerte, en 1679, abierto en 1680 a petición de su hijo Pedro Cayetano. El documento incluye la partición de sus bienes que da a conocer las riquezas artísticas que habría atesorado a lo largo de su vida y otras escrituras que proporcionan numerosas noticias sobre otros miembros de la familia ${ }^{17}$.

Su hermano Iñigo, casado con Ana González Legarda, con bienes en Indias y que le sobrevive, obtiene la Orden de Calatrava el año de 1659 coincidiendo, como es lógico, los lugares en que se llevan a cabo la las informaciones pero es curioso que la mayoría de las personas consultadas sobre el personaje hablan de su edad como de cerca a los 32 años o sea nacido hacia 1614, y que en las fechas citadas, 1659, es secretario de su Majestad «residente en Nápoles al servicio del Virrey» en aquellas fechas el Conde de Peñaranda ${ }^{18}$.

También aparece Iñigo en Madrid representando a su hermano en la toma de posesión de la Villa de Mejorada y del Patronato de su Iglesia en 1672 y ya se ha dicho que había cedido a su sobrino al Cargo de Escribano de mandamiento de la Real Hacienda de Nápoles en tierras italianas donde ya en 1670 había dado poder a Don Luis de Oyo, Conservador del Real Patrimonio del Sicilia para que cobre «lo que debiera aver de aquel reino de ث́̈icilia y en 1671 expide otro poder a nombre de Baltasar Bazán, Secretario de Estado de Milán para que liquide lo que se le concedía por una cédula de la Reina y librada a dicho estado italiano ${ }^{19}$.

Iñigo Fernández del Campo Angulo y Velasco, Caballero de Calatrava, Secretario de Majestad y su Secretario en la Cámara y Patronato Real, dicta testamento en 1688 fecha de su muerte en el que ordena se le entierre en la Cripta de los Agustinos de la que es Patrono su sobrino Pedro Cayetano ${ }^{20}$.

Los datos sobre el Pedro Cayetano Fernández del Campo segundo Marqués de Mejorada y de la Breña, cuya vida se prolonga hasta la año de 1721 , son menos claros en los documentos consultados por que incluso en la prueba para la obtención de la Orden de Alcantara no ha podido precisarse la fecha que sus viejos biógrafos fijan en el año de 1663, imposible

15 Estella, 1982, cit. nota 14: Mencionó la Testamentaría (Vid. nota 9).- Barrio Moya, J. L.: «Las colecciones de escultura y pintura del primer Marqués de Mejorada», Hidalguía, 1982, pp. 839-852, p. 843.

${ }^{16}$ APM, Protocolo n. ${ }^{\circ}$ 10058, Pérez Ortíz, 23 de agosto de 1673; Protocolo n. ${ }^{\circ}$ 13347, Munilla, J. B., f. ${ }^{\circ} 331 \mathrm{v} \mathrm{a}^{\mathrm{a}}$.

17 APM, Protocolo n. ${ }^{\circ}$ 10066, Pérez Ortíz, cit. nota 9; Estella, 1982, cit. nota 14 y Barrio, cit. nota 15.

18 Vid. nota 6: Órdenes Militares, Calatrava, Legajo. 2130, Exp. 891.

19 APM, Protocolo n. ${ }^{\circ}$ 9940, Eguiluz: f. ${ }^{\circ}$ 109, posesión de la Villa por Pedro Fernández del Campo (29-31672); f. 115 , poder a su hermano Íñigo para tomar posesión; f . 127 , derechos de la posesión (nombrar alcaldes, etc.); f. 138 , ejercicio de la jurisdicción, derecho de «orca y cuchillo...»; f. ${ }^{\circ} 378$, venta judicial de la jurisdicción, vínculo y vasallaje de la Villa y demás bienes en 26-4-1672; f. ${ }^{\circ} 126$, posesión del Patronato de la Capilla Mayor y Camarín de la Bóveda de la Iglesia de Mejorada en 13-3-1672, representado por su hermano Íñigo. Aún en Protocolo n. ${ }^{\circ} 10058$, Pérez Ortíz, en 11 de agosto de 1673, carta de pago a Pedro Fernández del Campo de la venta de la Villa y del Patronato de la Iglesia.- Cesión del cargo de Escribano de la Real Hacienda de Nápoles, vid. nota 16.-APM, Protocolo n. ${ }^{\circ}$ 10055, Pérez Ortíz: Poder a Luis del Oyo, 16-1-1670.— Idem. Poder a Baltasar Bazán, 16-3-1671.

20 APM, Protocolo n. ${ }^{\circ}$ 10067, Pérez Ortíz, Testamento de Íñigo Fernández del Campo a 7-5-1688. 
pues había nacido el 1656, según datos más fiables,como es el de la Capitulaciones Matrimoniales de sus padres. Las informaciones se realizan en tierras de Salamanca y del alto Aragón. La localización reciente de sus disposiciones testamentarias en una Memoria que adjunta a su Poder para testar delegado en su esposa, con la condición de respetar aquellas, ha aclarado muchas de las noticias confusas sobre su vida y obras emprendidas, como son las referidas a su matrimonio con Maria Teresa de Alvarado Bracamonte en 1681, acompañada de las correspondientes Capitulaciones matrimoniales o sus disposiciones para su entierro así como la de la fecha de su muerte, 19 de mayo de 1721 , u otras que se mencionarán en su caso ${ }^{21}$.

Para lo que interesa en este estudio se destaca únicamente su intervención tardía aunque definitiva en la Capilla de San Fausto de la Villa de Mejorada del Campo, la noticia dada por Kreisler Padín sobre su legado de esculturas napolitanas a la Capilla del Cristo de San Ginés y la que últimamente recogió Nappi sobre una Magdalena en madera que encarga al napolitano Fumo, para ser enviada a Madrid ${ }^{22}$.

Pedro Cayetano Fernández del Campo, Comendador de Peralada, Caballero de Alcántara, segundo Marqués de Mejorada, y de la Breña, nació pues en 1656. En el año 1705 alcanzó la secretaría de estado de la negociación de Italia y enseguida, como su padre, el cargo de Secretario de Despacho Universal.

En año de 1673 debió vender el Oficio de Escribano en Nápoles que le había cedido su tío pues en sus mencionadas Disposiciones testamentarias habla de que ha decidido vender el Cargo.En 1680 se ocupa de la testamentaría de su padre, que termina en 1687 y en 1685 declara que por muerte de su padre se hizo inventario de sus bienes en los que no se incluyeron tres cuerpos de santos y diferentes reliquias destinadas a la Capilla de Mejorada que estaban en el Oratorio de su casa ya que esperaba colocarlas en condiciones. Pasaron algunos años hasta que efectivamente se ocupa de la obra de la Iglesia. Como se ha dicho en estas Disposiciones que debió ir redactando en el trascurso de su vida, determina su entierrro en los Agustinos Recoletos de Madrid pero pide que su corazón se lleve a Guadalupe, noticia que en este mismo número confirma la Doctora M. ${ }^{a}$ Paz Aguiló, que completa este trabajo con sus aportaciones sobre el Legado de unos espejos y dos escritorios que el primer Marqués de Mejorada hizo a aquel cenobio ${ }^{23}$.

21 Vid. nota 6: Órdenes Militares. Alcántara. Legajo 509: como se aclaró la fecha de 1663 debe estar equivocada pues las Capitulaciones matrimoniales de sus padres fueron en 1653 (Vid. nota 9).- Álvarez Baena, cit. nota 9 y Protocolo n. ${ }^{\circ} 10066$, cit. nota 9 que también incluye la fecha de la muerte de su madre y el Inventario de sus bienes. El segundo Marqués de Mejorada murió en 1721.- APM, Protocolo n. ${ }^{\circ}$ 15007, Silvestre Barrio: Se inicia en f. ${ }^{\circ} 539$, rotulado «El Marqués de Mejorada. Testamento, 6 de junio de 1721». La Marquesa viuda dice que ha muerto el Marqués en su Casa de Viñuelas el 19 de mayo de este año 1721 y presenta el Poder para testar que le había dejado dese el año de 1702 en que dispone se atengan a la Memoria de 34 pliegos con sus disposiciones testamentarias y su testamento que también acompaña, documentos que se inician en $f^{\circ} 542$ hasta $f^{\circ} 618$ inclusive.

22 Barrio Moya, J. L.: «La Capilla de San Fausto en Mejorada del Campo», Cisneros, 1979, n. 76 (Recoge una cita de APM, Protocolo n. ${ }^{\circ} 12.278$, año 1688 sobre el trabajo encomendado al "carpintero Gabriel Marcos en la obra de Matías Román).- Kreisler Padin, M.: «Notas y noticias sobre la capilla de la Congregación del Cristo de San Ginés», Revista de la Biblioteca, Archivos y Museos del Ayuntamiento de Madrid, VI, 1929, pp. 333-352; p. 346.- Nappi, E.: «I Viceré e l'arte a Napoli», Napoli Nobilissima, 1983, pp. 4157: el año de 1705 , p. 57.

${ }^{23}$ Escudero, cit. nota 5.- APM, Protocolo n. ${ }^{\circ}$ 10058, cit. en nota 16: le ceden el cargo de Escribano en Nápoles a Vilani italiano?-Vid. nota 21. Disposiciones testamentarias, f. 364 v. ${ }^{\mathrm{a}}$ - - APM, Protocolo n. ${ }^{\circ} 10066$, cit. nota 9: incluye la declaración de 1685. - Disposiciones testamentarias, cit. nota 21. - Vid. en estas páginas: Aguiló, M. ${ }^{\mathrm{a}}$ P.: «Otros objetos italianos representativos del mecenazgo de los Mejorada en el Monasterio de Guadalupe». 


\section{LAS OBRAS ARTÍSTICAS PATROCINADAS POR LOS MARQUESES DE MEJORADA}

\section{Sus sepulcros en los Agustinos recoletos de Madrid}

Al primer Marqués de Mejorada se debe la construcción de la Capilla Mayor del desaparecido convento de Agustinos Recoletos de Madrid, cuyo patronato compra en el año de 1671. No queda nada de aquel convento tras la Desamortización, compradas sus posesiones curiosamente por el propio Mendizábal según González Palencia. En trabajo anterior se habló de aquella obra de su Capilla Mayor, cubierta «con media naranja, linterna e zimborrio» de autor no mencionado pero cuya obra controlaría Fray Pedro, no Fray Lorenzo, de San Nicolás, profeso en el Convento y maestro de obras ${ }^{24}$.

Se localizaron en los depósitos del Museo Arqueológico Nacional los Orantes en mármol de Pedro Fernández del Campo y su esposa Teresa Salvatierra (Figs. 1 y 2) que aunque deteriorados son el único resto de aquella empresa en la que intervinieron los mejores artistas madrileños de aquellos años, equipo similar en muchos nombres al que al tiempo se ocupa de la Capilla de San Isidro pero que no se ocuparon de las bellas esculturas traídas de Génova con su memoria para asentarlas. Tampoco aclararon los documentos el autor de estos sepulcros que como se sugiere más adelante con más fundamento fueron llevadas a cabo en Génova por modelos del pintor Carreño de Miranda, el tasador de la colección pictórica del Marqués ${ }^{25}$.

Los Orantes, que presidían a un lado y otro a la Capilla Mayor del Convento, colocados en nichos del crucero según los describió Ponz, hubieran de ser reparados a su llegada por el marmolista Carlos Gautier, posiblemente por el apellido procedente del Franco Condado tierras que por aquellos años se perderán para España y de donde proceden varios artífices localizados en Aûeestras tierras en su éxodo camino de Italia, como Claudio David, escultor de marfil que trabaja en mármol en la fachada de la Catedral de Génova. Carlos Gautier «se obliga a dar sentada toda la obra de piedra de diferentes mármoles que ha benido de Génova y está en dicho convento y respeto a que biene maltratada la ajustara. conforme a la memoria que se enbio de Génova», frases que nos hablan de los típicos revestimientos de marmi intarsiati o commesso tan utilizados en Nápoles. como en Génova, por aquellos años. Sigue la escritura aclarando que pondrá «asimismo la piedra que falta de mármoles con la referencia de colores que demuestra la planta y alçado que hiço Francisco de la Viña», artista flamenco residente en Madrid, que trabaja también en la capilla de San Isidro y que debía conocer esta técnica del taraceado de mármoles ${ }^{26}$.

Estudiados en su día los Orantes sólo puede añadirse ahora que quizás fuesen obra del artista al que como se dirá, se encarga ahora un magnífico retablo de mármoles de distintos colores para la Capilla de San Fausto en la Iglesia de Mejorada del Campo, Patronato de los Fernández del Campo.

De Don Iñigo no se conoce empresa artística concreta pero ya se ha mencionado su presencia, en nombre de su hermano, en la toma de posesión del Señorío de la Villa de Mejorada, donde años más tarde se realiza una las empresas artísticas de más importancia de la corte madrileña de los años finales del siglo XVII bajo el patronato de Pedro Cayetano, el segundo Marqués de Mejorada, iniciada en parte por su padre.

24 Estella, M.: Estatuas funerarias, 1982, cit. nota 14: recogè la bibliografía y la documentación sobre el tema incluido en el trabajo de González Palencia, «El Convento de los Agustinos», cit. nota 5.

25 Estella, M.: 1982, cit. nota 14.

26 Ponz, A.: Viaje de España, Madrid, Aguilar, 1947 (de la edición de 1772-1794), p. 423.—Estella Marcos, M. y Barrio Moya, J. L.: «Actividad documentada en Andalucía de dos escultores en marfil del Franco Condado», Revista de arte sevillano, n. $^{\circ}$, 1983, pp. 17-25.-Macho Ortega, cit. nota 4; p. 222, sobre Francisco de la Viña. 


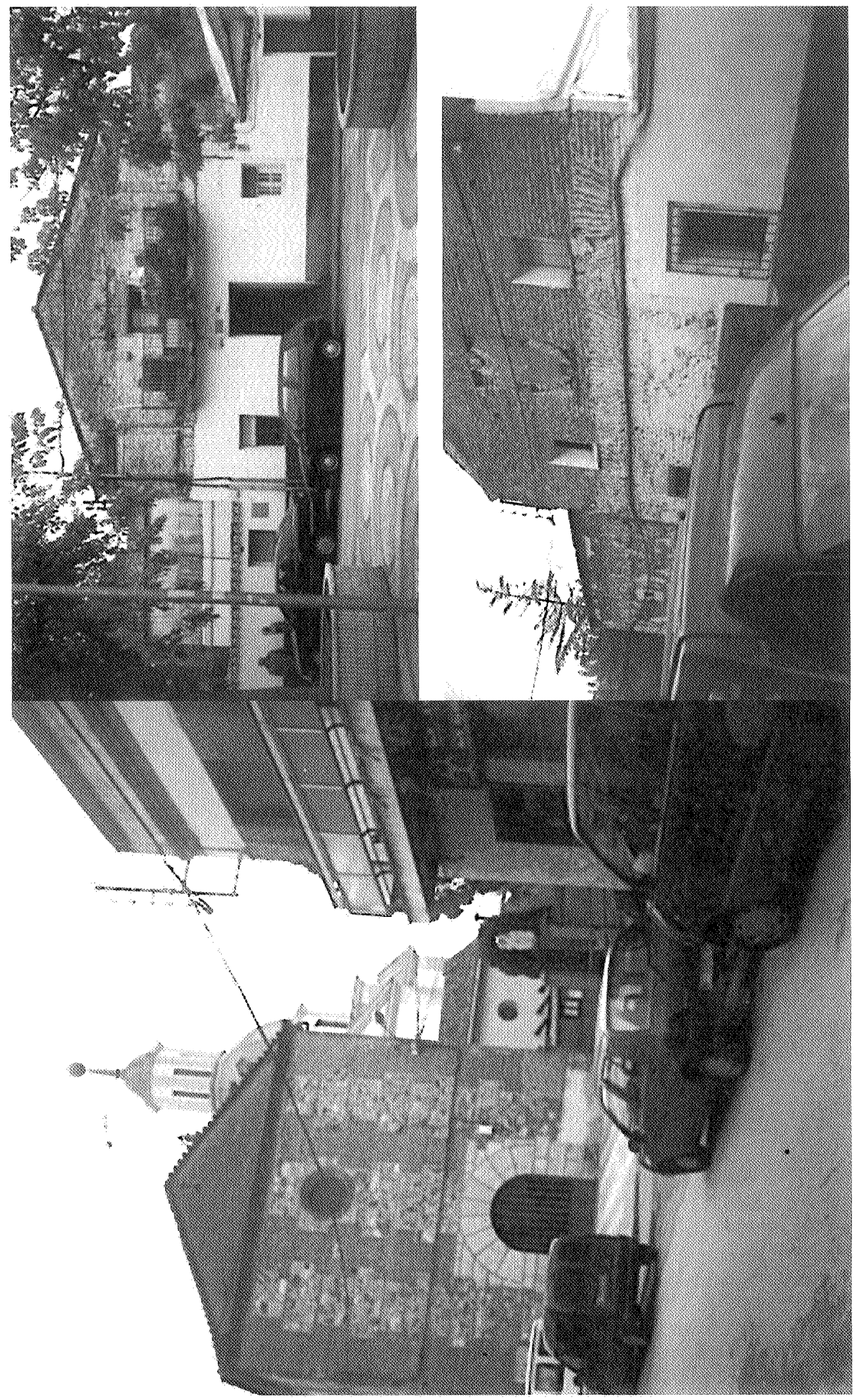

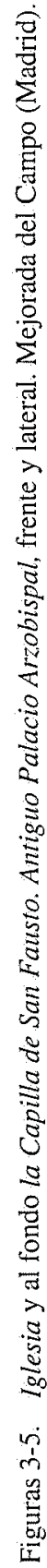




\section{Las construcciones de Mejorada del Campo}

Por las escrituras otorgadas ante el Escribano Eguiluz se sabe que D. Pedro Fernández del Campo, Primer Marqués de Mejorada, a los muy pocos años de su nombramiento como Secretario del Despacho Universal de 1669, había comprado el Señorío de esta Villa de Mejorada a Francisco Fernández de Heredia tomando posesión de la Villa su hermano en su nombre el 29 de marzo de 1672, con los derechos a ello anejos: posesión de tierras y bodegas, ejercicio del derecho de «orca y cuchillo, cordel y açote» es decir de la administración de justicia conforme a derecho ${ }^{27}$.

También compra el mismo año el Patronato de la Capilla Mayor de la iglesia de la Villa y Bóveda y entierro en ella.

Muy poco después, en agosto de 1673 el Primer Marqués de Mejorada encarga a Joseph Arroyo, maestro de obras madrileño, la realización de unas casas en la villa. En efecto en Madrid a 24 de mayo de 1673 comparecen, ante el notario Pérez Ortiz, Pedro Fernández del Campo, Marqués de Mejorada y Joseph Arroyo, maestro de obras el cual dice que por orden de dicho Marqués había empezado en Mejorada, en las casas y sitio que su Señoría había comprado de Pedro de Frías y sus hermanos, la obra de un mesón ya liquidada la parte de sus cimientos y tapia y que ahora piensa concluir en las condiciones que se estipulan por un precio de 36.000 reales de vellón. Habrá dos viviendas con su patio cada una y entradas de puertas para la servidumbre según la planta aceptada para la obra por el Marqués y firmada por Arroyo. Se determina como se han de constituir unos pilares del edificio, su cubierta, alero, paneles, etc y se dice que cada una de las dos viviendas tendrá su chimenea y su copina y se constituirán doce plazas de pesebres. La obra la revisará Thomas Aspur, que posteriormente tasará los bienes inmuebles del marqués.

Las precisas condiciones indican una mansión dividida en dos viviendas con numerosos salones provistos de chimeneas y un número apreciable de pesebres para las caballerías. No se ha localizado ninguna otra noticia sobre el edificio que según aparece se corresponde con el antiguo Palacio Arzobispal, en la actualidad una pobre casa de viviendas (Figs. 4 y 5) de las que se ha pedido su restauración y que, según dijeron en el Ayuntamiento y los habitantes de la casa, conserva aún un túnel que comunicaba precisamente con la Capilla de San Fausto construida años después, aneja a la Iglesia. Lo único que sí se aprecia en la actualidad es que efectivamente constaba de dos bloques de viviendas separadas por un espacio con un patio a cada lado ${ }^{28}$.

El mismo maestro de obras, Joseph Arroyo, realiza para el Marqués un molino en tierras que poseía en la vecina villa de Rivas. El maestro Joseph Arroyo el Mayor firma el contrato con su hijo Joseph Arroyo en el que se comprometen a terminar la obra del molino que está en el Soto de Negralexo en la Villa de Rivas, próximo a las tierras del Conde de Barajas. Se encargarán de hacer la obra del «voca caz» y «presa Real» que falta, abrir los cauces desde la presilla del Conde de Barajas hasta llegar al estanque del Molino. La planta del «voca caz»

27 Vid. nota 19, Protocolo n. ${ }^{\circ} 9940$, f. $^{\circ} 138$ y f. ${ }^{\circ} 126$ derecho al ejercicio de la jurisdicción.

28 APM, Protocolo n..$^{\circ} 10058$, Pérez Ortiz (sin foliar cuando se consultó): 24 de mayo de 1673 - - Al parecer después de nuestra visita en octubre de 1999 se ha decidido derruirla conservando sus bodegas — ¿el túnel?y una pared lateral, único resto, parece, de la antigua construcción que, dado su estado actual, no facilita la identificación de una casa señorial y hace pensar que quizás sólo constituía parte de sus dependencias. El Palacio o Casa Señorial existió pues se incluye en el Inventario de los bienes del Primer Marqués (APM, n. ${ }^{0}$ 10066, cit. nota 9) y de él se habla en las Disposiciones Testamentarias del Segundo Marqués (cit. nota 9) y en APM, Protocolo n. ${ }^{\circ} 13345$, que más extensamente se refiere en sus f. ${ }^{\circ}$ s 14 y ss. «al Palacio, Caballerizas y demás casas y pajares...». 
ha de ser encajonada de piedra y cal. Después de ir describiendo la obra que ahora debe hacerse en cada una de las partes que constituyen el conjunto, determinando hasta como se han de mezclar los materiales como por ejemplo cuando dice que la piedra ha de ser la que se ha gastado en dicho molino de pedernal y las mezclas han de ser de a dos espuertas de arena y una de cal, se estipula el tiempo de entrega en cuatro meses, y los plazos del pago, firmando el concierto los maestros, padre e hijo, y el Marqués. El precio convenido y las condiciones muestran conocimientos técnicos de cierta consideración y si bien era obra común y necesaria en todos tiempos, como se ha constatado por ejemplo en Madrid, en relación con los Summonte en el Madrid del siglo XVI, ya se planean con un cierto aspecto de una empresa económica de interés que en estos años parecen preludiar el espíritu ilustrado que fomenta obras similares, como la de Goyeneche en el Nuevo Baztán personaje con el que efectivamente se relacionaba el Marqués ${ }^{29}$.

A partir de estas fechas no parece que el Primer Marqués vuelva a preocuparse de su Villa de Mejorada, quizás entretenido con la gran obra emprendida casi al tiempo en el Convento de Recoletos Agustinos de Madrid y en marcha en estos años. También debe pensarse que ya se acercaba a su muerte acaecida en el año de 1680 y que la turbia política de la Corte española en la que se hallaba sumergido agotó toda su actividad.

En cualquier caso debió quedarle tiempo para ocuparse de su colección de pinturas y esculturas, muchas de ellas recibidas de su esposa Teresa Salvatierra como puede comprobarse comparando los inventarios respectivos de cada uno de los miembros del matrimonio, realizado el de la esposa a su muerte en el año de 1666. Dimos noticia de la colección en el trabajo que dedicamos al estudio de los sepulcros conservados en el Museo Arqueológico, y en la misma fecha Barrio publicó por extenso su contenido, tasadas las pinturas por Juan Carreño de Miranda y las esculturas por Pedro Alonso de los Ríos ${ }^{30}$.

El año de de 1685 marca el inicio de las empresas artísticas del Pedro Cayetano Fernández del Campo, Segundo Marqués de Mejorada y de la Breña título que recibió de su esposa María Teresa Alvarado Bracamonte de la que, como se ha comentado, no se ha localizado la quizás relación familiar con el Conde de Peñaranda, Don Gaspar de Bracamonte, el Virrey de Nápoles a cuyo servicio estuvo Iñigo Fernández de Córdoba ${ }^{31}$.

Como se ha dicho en esta fecha, Pedro Cayetano ocupado aún con la testamentaría de su padre declara que no se pusieron por Inventario tres cuerpos de santos y diferentes reliquias que tiene en su oratorio en Madrid y por ello no se mencionaron los cuales su padre le dijo verbalmente que las colocase «en la capilla Mayor de la Iglesia de Mejorada» y que no lo había hecho pues quería «ponerlos donde estén con decencia y veneración» ${ }^{32}$.

Parece que esta decisión se lleva a efecto con la obra de la preciosa Capillita de San Fausto adosada a la Iglesia de Mejorada que según noticias dadas por Barrio se lleva a cabo por los años de 1688 por Matías Román, otro maestro de obras madrileño bajo cuya traza

29 APM, Protocolo n. ${ }^{\circ}$ 10270, Merino, f. ${ }^{\circ}$ s 435-439v. ${ }^{\text {a }}$ - APM, Protocolo n. ${ }^{\circ} 145$, Riaño, f. ${ }^{\circ}$ s $379-380$ : Catalina Ruiz, viuda de Sebastián de Hita, carpintero, se compromete el año de 1550 sobre la obra «de un molino de quatro ruedas en la ribera del rio... de Madrid que su marido se obligó a hacer al Contador Fernando de Summonte...».- Sobre la relación con los Goyeneche: Disposiciones Testamentarias, cit. nota 21, Protocolo n. ${ }^{\circ} 15007$, f. $^{\circ} 590$.

${ }^{30}$ APM, Protocolo n. $^{\circ} 10066$, tantas veces citado, en las notas 9,15 y 21: Carreño de Miranda fue también el tasador de la colección de pinturas de Teresa Salvatierra, año 1666.

31 Vid. nota 12 y APM, Protocolo n. 13344 , f. 95 : Por ejemplo Poder de la Marquesa de la Breña que sucede en los Vínculos y Mayorazgos a su padre Diego Alvarado Bracamonte, Marqués de la Breña.

32 Vid. nota 23, Protocolo n. ${ }^{\circ}$ 10066: sobre disposición de los cuerpos santos en 1685. 
elevará su cúpula encamonada el carpintero Gabriel Marcos (Fig. 3). Siguiendo ahora a este autor y la bibliografía por el empleada, se sabe que la Capilla de San Fausto fue fundada por el segundo Marqués de Mejorada, Pedro Cayetano, y que la licencia Pontificia la otorgó el Cardenal Portocarrero el año de 1687 siendo inaugurada el año de 1691 aunque Elena Santiago Paéz fija la fecha de su consagración en 1699, que dio Ponz. «De planta central con muros de piedra en los que destacan tres frentes que se corresponden al interior con tres bóvedas de horno. La cúpula está cubierta por una media naranja con tambor y linterna realiza- da en pizarra sobre armazón de madera» llevada a cabo por el carpintero Marcos según planta y alzado de Matías Román. Este mismo maestro, yerno de Aspur, el tasador de los inmuebles del primer marqués de Mejorada, se ocupará de la reforma de la Capilla Mayor de la Iglesia en la que el segundo Marqués de Mejorada decide instalar unos nichos para depositar en ellos el resto de las reliquias que había reunido y alhajarla con un retablo de mármol de lo que se hablará más adelante ${ }^{33}$.

\section{El Altar-Baldaquino de la Capilla de San Fausto, obra siciliana}

Su precioso interior, muy italiano presentaba la incógnita de su magnífico Baldaquino central y las esculturas en mármol que se distribuyen en nichos en los machones que sostienen la cúpula. Elena Santiago Paéz recordó su descripción por Ponz que destacó su peculiar estructura, de planta de cruz griega que sostiene la cúpula por cuatro arcos y máchones en los que hay, «dos nichos en cada uno y dentro de ellos estatuas de mármol y aunque la de San Antonio de Padua, San Francisco de Asís, San Diego y San Pedro de Alcántara no son gran cosa, las que están debajo, San Vicente Ferrer, San Ignacio, San Javier y Santo Domingo son muy razonables, de manera italiana», disposición que han conservado aunque fal$\tan$ algunas de las esculturas descritas. También describe el «Altar aislado con cuatro frentes con sus frontales con embutidos de piedras diferentes. Pedestal de lapislázuli, alabastro y otras piedras y en sus ángulos, angelitos de bronce» que se han perdido, como la urna, también siguiendo a Ponz, depósito del cuerpo de San Fausto, sin duda uno de los tres que menciona el segundo Marqués de Mejorada en $1685^{34}$.

Elena Santiago Paéz, la primera autora que en estos años se ocupó de esta capilla y su decoración pensó que quizás fuese obra napolitana de por ejemplo Carlo Fanzago que se encontraba en Madrid al menos hasta 1678 que se le comunica la muerte de su padre Cósimo Fanzago, el gran artista del barroco de Nápoles que había trabajado para España, concretamente en la fundación de los Monterrey en Salamanca. Las esculturas, como se dirá, aparecen en este entorno cultural pero en realidad su ejecución se llevó a cabo en Génova, como se ha documentado ahora y el Baldaquino no respondía exactamente a la labor de marmi intarsiti o de commesso que se practicaba en Nápoles, opinión que confirmó personalmente el Prof. Ruotolo en una visita a esta villa el cual además sugirió su aire siciliano.

33 Ponz, cit. nota 26, p. 103-- Barrio, La Capilla de San Fausto, 1979, cit. nota 22.- Santiago Páez, E.: «Algunas esculturas napolitanas del siglo XVII en España». Archivo Español de Arte (AEA), 1967, pp. 115132. - APM, Protocolo n. ${ }^{\circ} 15007$, cit. en nota 21, f. ${ }^{\circ}$ 556.- Sobre la relación de Matías Román con Aspur, del que es yerno: AHN, Libro 6782, Legajo n. ${ }^{\circ}$ 1688, de la Sección del Clero. Madrid. San Agustín.

${ }_{34}$ Vid. notas 23, 32 y 33. 

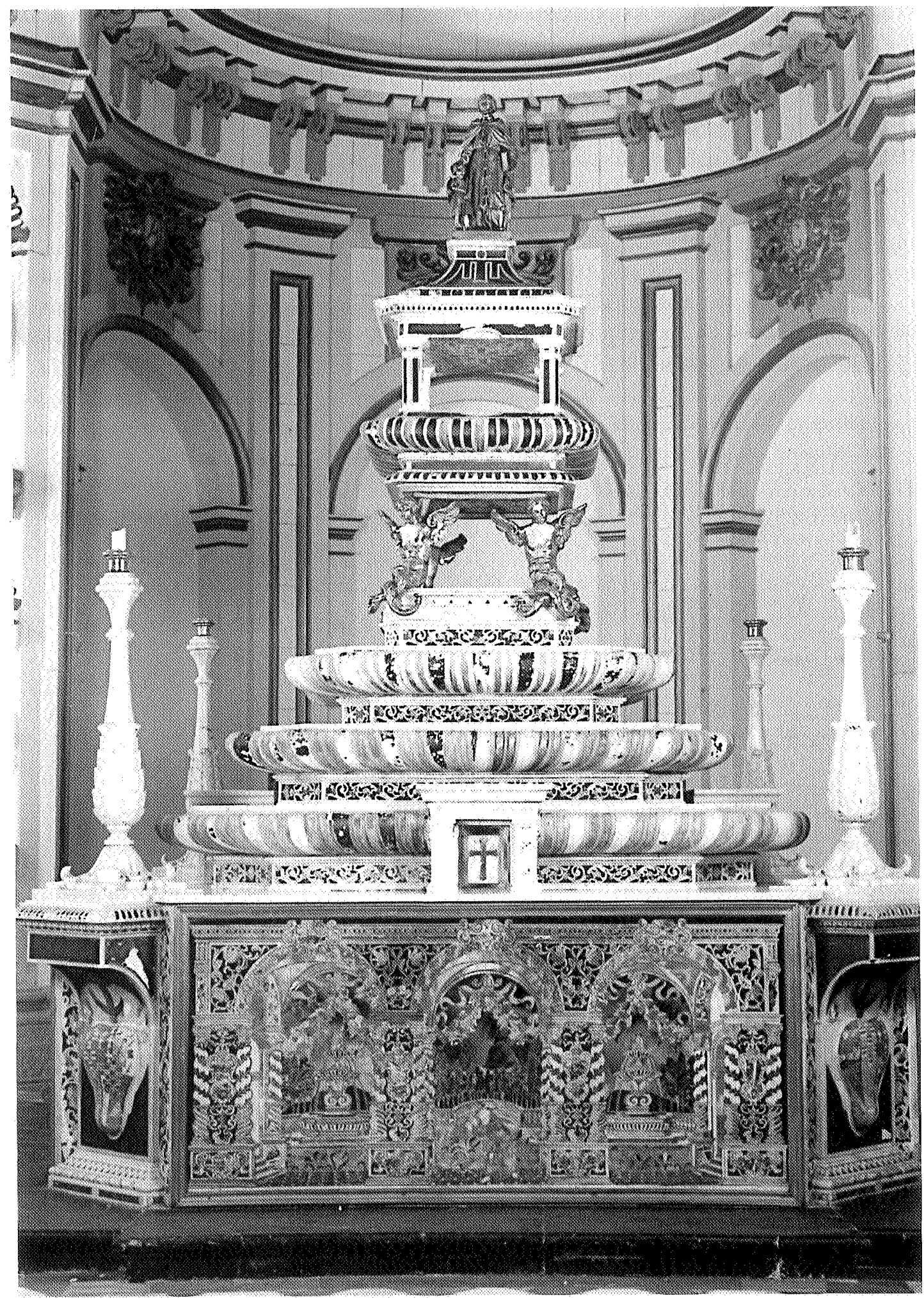

Figura 6. Altar-Baldaquino. Mejorada del Campo (Madrid). Iglesia. Capilla de San Fausto. 

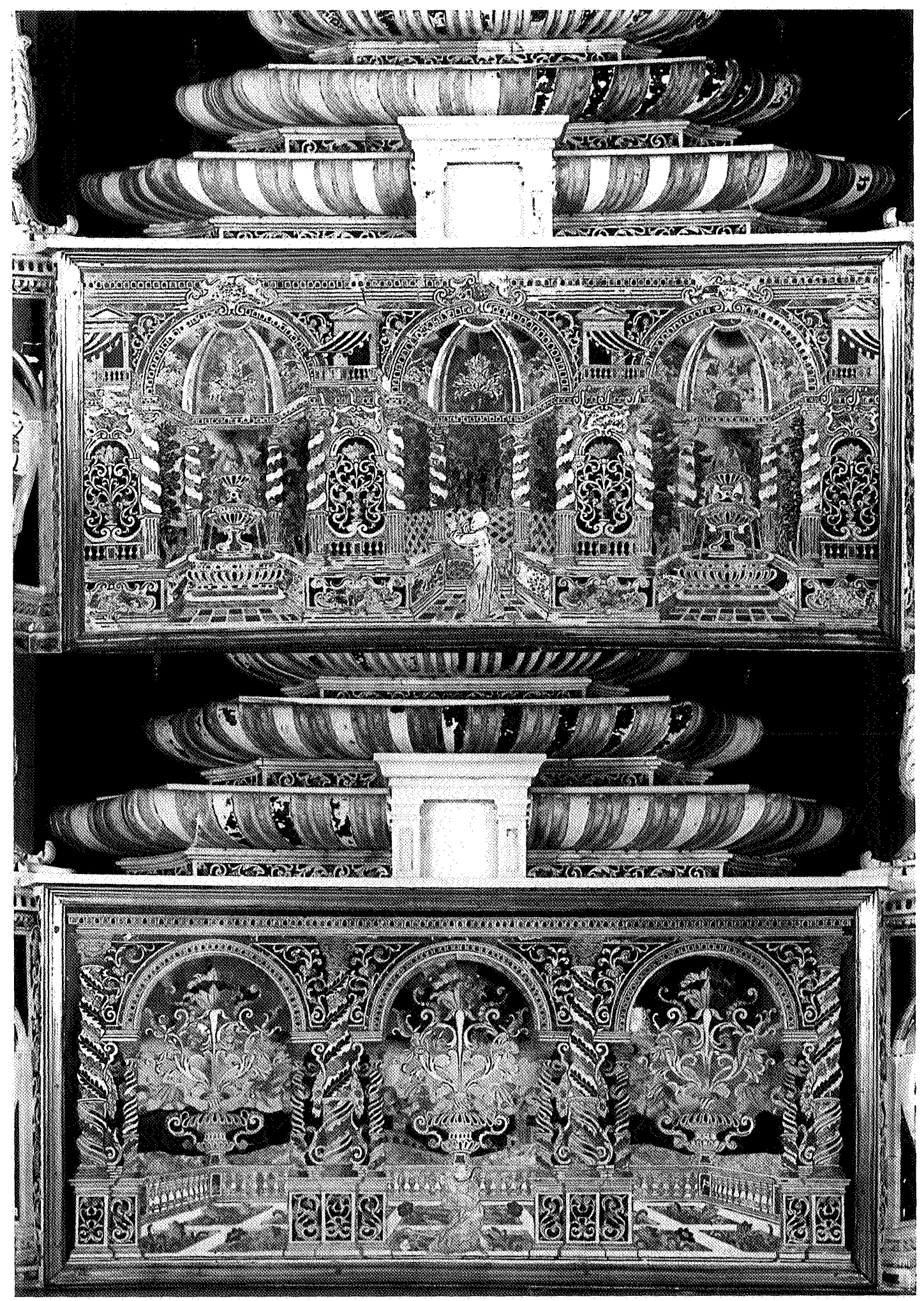

Figuras 7 y 8. Frontales o «Paliotti» del Altar-Baldaquino. Mejorada del Campo (Madrid). Iglesia. Capilla de San Fausto. 
Prosiguiendo las investigaciones por fin se ha localizado la documentación sobre la construcción de este Baldaquino en Palermo y su posterior envío a España. También se documentó el encargo de un retablo de mármoles para la Capilla Mayor de su Iglesia al maestro Francisco Abril del que sabemos por la Memoria con las disposiciones testamentarias del Marques que no llegó a realizarlo por su muerte y que en realidad ello decidió a pensar en Sicilia para la obra del Altar de la Capilla de San Fausto. Posiblemente en esta línea de preferir los talleres de Génova para las obras en mármol Pedro Cayetano Fernández del Campo encargará a esta ciudad las esculturas de los Santos por mediación de Don Francisco Grillo como se ha sabido ahora con la lectura de las cláusulas testamentarias de la citada Memoria ${ }^{35}$.

En medio de la capilla se yergue este magnífico Baldaquino (Fig. 6). Asentado en alto pedestal cuadrado con las esquinas achaflanadas, decorados sus frentes de preciosos marmi intarsiati con la técnica de la decoración a mischio o commesso, se eleva entre cuatro candelabros de blanco mármol y esbelta silueta una especie de pirámide escalonada compuesta de tres cuerpos en forma de urnas decoradas con gallones polícromos de la misma técnica. Sobre este cuerpo en sus cuatro esquinas deliciosas figuras,arpías según uno de los documentos, en bronce dorado de colas enroscadas sostienen un templete apoyado en un cuerpo bajo del mismo perfil que los del cuerpo inferior que deja un espacio hueco entre pequeñas pilastras coronadas por un cuerpo de caras cóncavas triangulares truncadas sobre los que aparece la figura de San Fausto, más tosca, en bronce dorado, con una larga cadena al cuello, un libro bajo el brazo derecho y un ángel de menor estatura que la del santo a la izquierda con una vara en la mano (Figs. 7-9 y 12-13).

En la búsqueda de los posibles artífices de tan bello monumento se revisó una amplia documentación sobre los Patrones de la Capilla, los Fernández del Campo, advirtiendo, como se ha especificado, la estancia de Iñigo en Nápoles y los haberes debidos a su nombre que ordena cobrar en Sicilia. Sobre Pedro Fernández del Campo se supo, por noticias poco precisas de González Palencia, que había estado en Milán, pero no se insistió en la búsqueda por las fechas, posteriores a su vida, de la construcción y ornato de Capilla de San Fausto en la que como se ha dicho no interviene prácticamente reduciéndose su actuación en la Villa de Mejorada a la realización de unas casas y un molino. La obra de la Capilla se lleva a cabo en los años de la vida de Pedro Cayetano Fernández del Campo, segundo marqués de Mejorada, cuyos encargos de escultura a Nápoles son bien conocidos, como son las imágenes del Cristo caído y un Ecce Homo de Nicolás Fumo y el Cristo a la columna de Giacomo Colombo en la Capilla del Cristo de San Ginés, a las que se le puede añadir una Magdalena que según Nappi ordena enviar a Madrid cuya descripción, "Contemplante un Crocifisso alle mani, dell'Altezza al naturale di palmi 6 e mezzo, oltre sobre la pedagna, che dobrá essere di pero nero adornata... d'intagli dorati e la statua tutta de legname parte vestita di stola apparente, parte nuda e parte coverta di panneggiamente e capelli», recuerda la de San Felipe Neri que Pedro de Mena pocos años antes (1664) había enviado a este Convento de Madrid y pudo ser modelo impuesto al escultor napolitano ${ }^{36}$.

${ }^{35}$ Páez, S.; cit. nota 33.- Madruga Real, A.: «Cósimo Fanzago en las Agustinas de Salamanca», Goya, n. ${ }^{\circ}$ 128, 1975, pp. 291-297.- Dombroski, D.: «Nápoles en España. Cósimo Fanzago, Giuliano Finelli. Las esculturas del Altar Mayor de las Agustinas de Salamanca», Anuario del Departamento de Historia y Teoría del Arte (Departamento de Arte de la Universidad Autónoma de Madrid) 1995/96, 87-93. - La documentación mencionada se citará en el estudio de las escrituras que la integran y las obras a las que se refieren.

${ }^{36}$ Vid. nota 32 (Kreiler Padin, Nappi).— Gómez Moreno, M. ${ }^{a}$ E.: Escultura del siglo XVII, Madrid, Plus Ultra, 1963 (Ars Hispaniae, XVI), p. 253: Casa Profesa o de la Visitación de «San Felipe Neri», advocación posterior a la de la Casa Profesa. Firmada Málaga, 1664. 

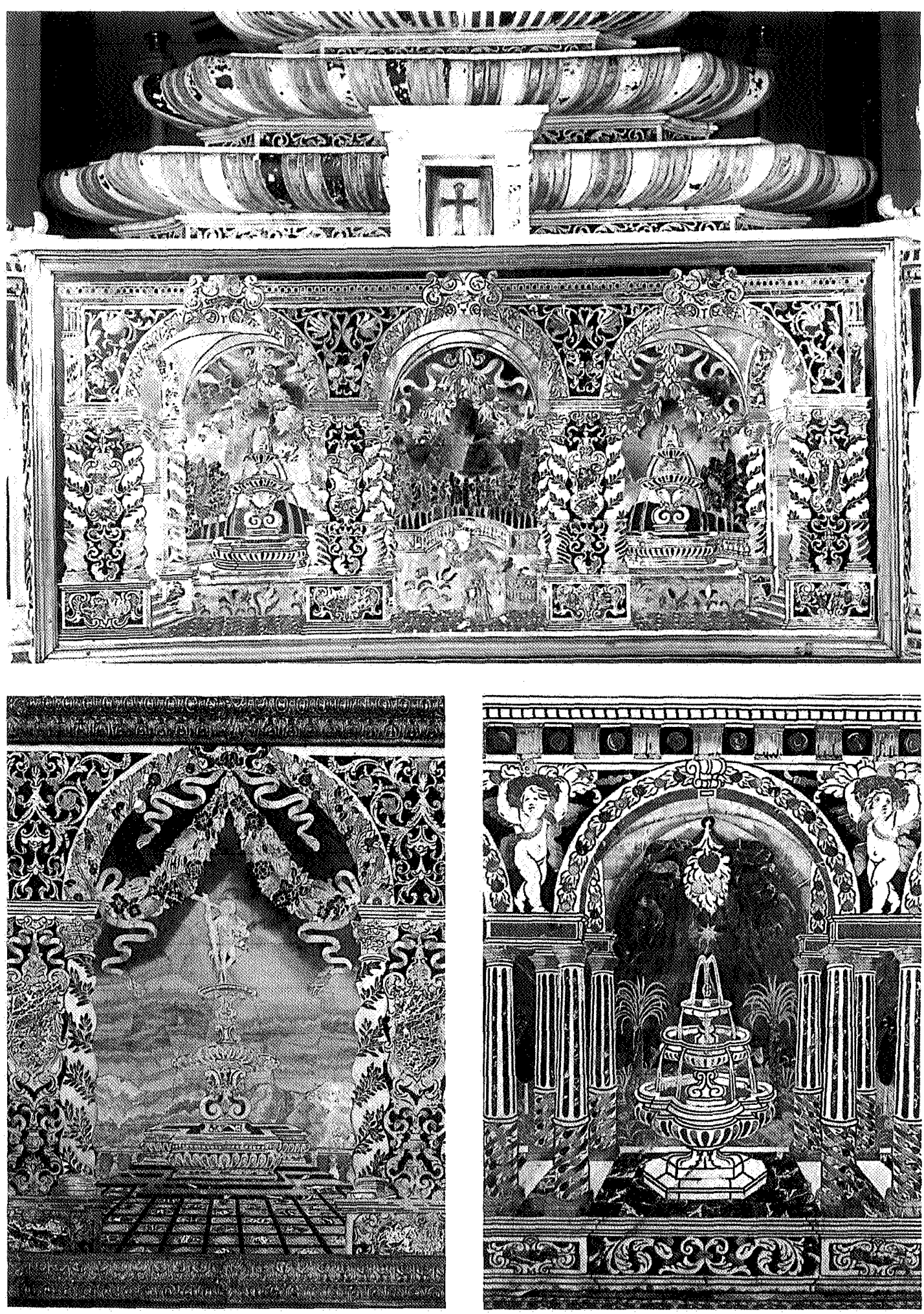

Figuras 9-11. Frontal del Altar-Baldaquino. Mejorada del Campo (Madrid). Iglesia Capilla de San Fausto. Paliotto a tarsia marmorea. Palermo, Catedral, hoy en Gibilmanna, Santuario. Paliotto a tarsia marmorea. Gioiosa Marea. Iglesia Madre. 
En cualquier caso no parecía que estos datos resolvieran el problema de la autoría del Baldaquino, extraño a otras numerosas importaciones de obra italiana en España incluida la del trabajo de mármoles polícromos, como la realizada por Cósimo Fanzago para la Iglesia de las Agustinas de Salamanca, por encargo del Conde de Monterrey que se mencionó antes.

$\mathrm{Al}$ fin, entre las numerosas escrituras que el Archivo de Protocolos de Madrid conserva sobre esta familia de los Mejorada, se localizaron unos preciosos documentos que de forma taxativa y en cierto modo minuciosa, documentan este monumento. Junto a estas escrituras también se encontró otra referida a un retablo de mármol para la capilla Mayor de Mejorada cuya descripción no se ajusta al conjunto de esculturas en este material que allí se conservan pero pudieron también documentarse como procedentes de Génova en las Disposiciones testamentarias del Marqués. La lectura de estos documentos sobre el Baldaquino da idea clara del encargo, los nombres de los artistas que en el intervinieron en sus distintas partes y el proceso seguido en su construcción. Por el interés de su contenido que no solamente proporciona el nombre de los autores de la obra sino también datos sobre el proceso seguido por esta técnica de los marmi intarsiati, marmi mischi o commesso se da una transcripción abreviada de todos ellos. En orden distinto al que se les da en este trabajo, interesa destacar en primer lugar una de de las escrituras sobre el Baldaquino con la relación de las otorgadas, todas ellas protocolizadas el mismo día y año, ante el mismo notario y ciudad.

Este primer documento protocolizado ante el escribano Munilla en Madrid a 20 de octubre de 1692 expone que Pedro Cayetano Fernández del Campo, primer Marqués de Mejorada «dixo que para executar y fabricar todas las obras que se necesitare para un tabernaculo que al glorioso San Fausto Confesor se está haciendo de orden dël Sr. Otorgante en la ciudad de Palermo en primero de septiembre pasado de este año ante Joseph Furino notario palermitano se otorgó escriptura por el Ser. Varon Trofe (??), D. Jemo. Pecha en que se hace mención a otras cuatro escrituras ... de diferentes conciertos hechos y la una es otorgada por D. Agustín Verstigui Egora oficial de la Secretaría de Estado y guerra del Reyno de Sicilia en nombre del SR. Otorgante de la una parte y de la otra Andrea Ateymingarí(??), Juan Antonio Gerardo y Caetano Cignorelli.. de mancomun... como principales y Franco Gargan como su fiador todos plateros en la dicha ciudad de Palermo. Otra otorgada por el dicho Agustín en nombre del dicho Sr. Otorgante de la una parte y de la otra Joseph Diamante arquitecto y pintor. Otra otorgada por el dicho Sr. D. Agustín de la una parte y de la otra Carlos Faulisi y Piscatore Guiçillerio artífices de obra de lapizlazolo. Y la otra otorgada por el dho Sr. D. Agustín de Verstigui Egora en nombre del Sr. Otorgante de la una parte y del otra Joseph Ragusa Mro marmolista como principal y Jacomo Picalupo y el Mro. Salbatore Cormasizerdo como sus fiadores y el dicho Sr. Varon en nombre del dicho Sr. Otorgante y como fiador de don Agustín de Verstigui sea obligado por la escriptura.. que dara y pagará a los dichos artífices las cantidades que en las otras cuatro escrituras se declara. El dicho señor Varón tiene orden del otorgante. y de Doria Musio residente en esta corte para executarlo como consta de cartas misivas.. Otorga y aprueba y ratifica en todo y por todo la dicha escritura y se obliga el Sr. Otorgante a poner en poder del dicho señor Varón todas las cantidades que en su nombre pagare por pólizas de dicho Agustín de Verstigui» firmado en esta corte por El Marqués de Mejorada ante Juan Bautista Munilla ${ }^{37}$.

Las escrituras citadas en este documento se transcriben una a una para su aprobación por el Marqués de Mejorada. En su orden lógico, no seguido en el protocolo, sigue la de la obligación contraída con el arquitecto.

${ }^{37}$ APM, Protocolo n..$^{\circ} 13337$, J. B. Munilla, f..$^{\circ}$ 401-402. 


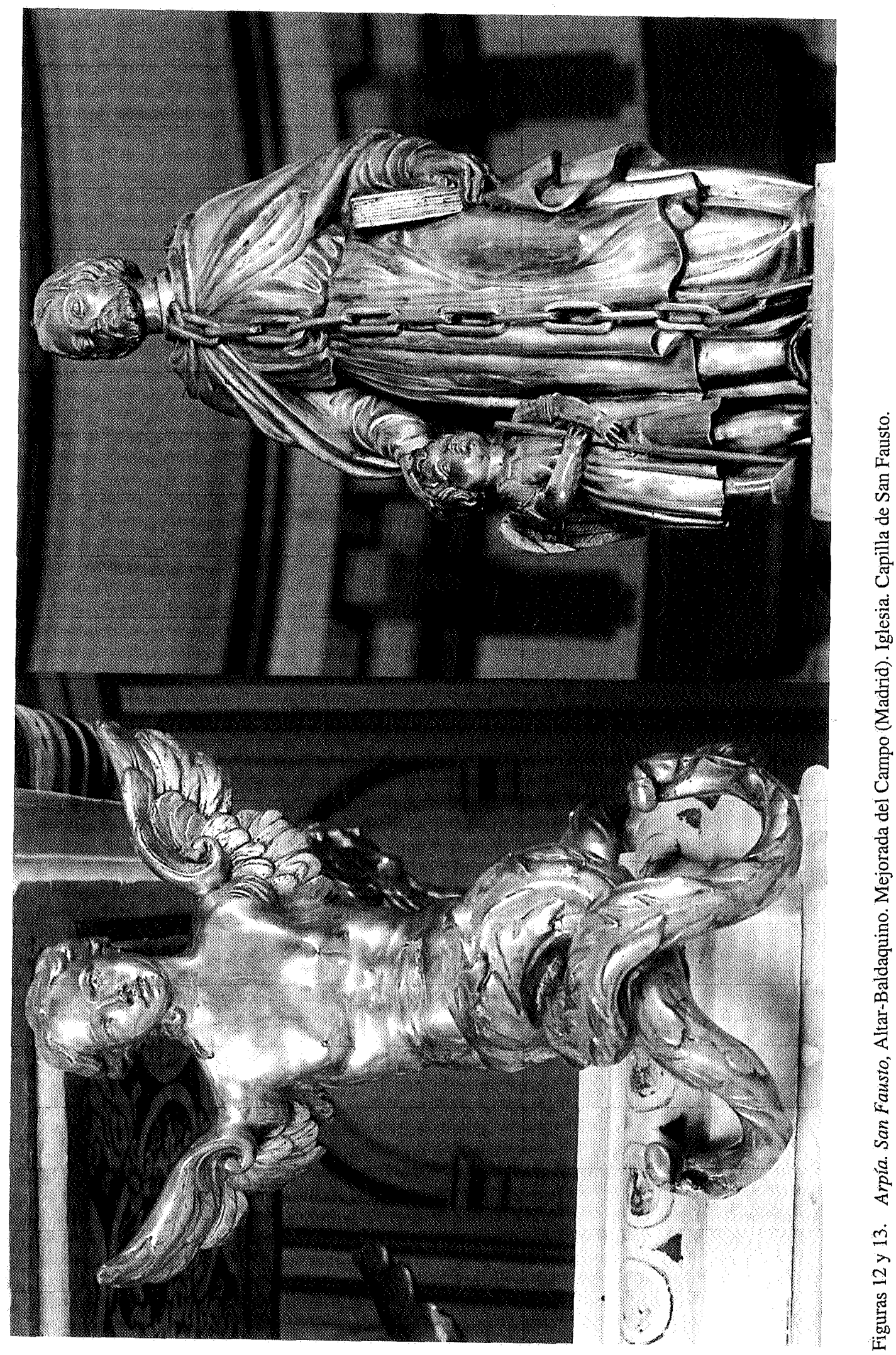


Como la escritura mencionada, ésta se otorga en Madrid el 20 de octubre de 1692 con el mismo escribano ante el cual el Marqués de Mejorada expone que en primero de septiembre de este año ante el notario palermitano Furino se otorgó escritura entre Agustín de Verstigui Egora de una parte y de la otra «Joseph Diamante arquitecto y pintor que se ha obligado el suso dicho asser superintendente de toda la obra del tabernáculo que en dicha ciudad de Palermo se ha de executar. para una capilla al glorioso San Fausto confesor y asistir y intervenir con todos los artífices que concurren en su excon siendo director de ellos y cuidando de que la obra vaya bien y fielmente ejecutada en el todo y en sus partes conforme a lo diseños y medidas remitidas para ello como en dicha escritura se contiene y dicho don Agustín en nombre de dicho señor otorgante se ha obligado al dicho señor Josef Diamante en recompensa y gratificación de todo lo que en esto hasta aquí ha trabajado y trabajase hasta su entero y cabal fenecimiento sessenta onzas de moneda de Sicilia a los plazos y, en dicha escritura se contiene y el Sr otorgante.. Otorga ratifica. la dicha escripra y se obliga con sus vienes..» Firma el Marqués ante Munilla ${ }^{38}$.

La escritura que se transcribe a continuación tiene gran interés pues en ella se describe el monumento. Con los mismos preliminares que las escrituras mencionadas, es decir otorgadas en Madrid en veinte octubre 1692 el Marqués de Mejorada declara que en Palermo, ante el notario Furino el primero de septiembre se había otorgado escritura entre el Verstigui y «Joseph Ragusa maestro marmolista como principal y Jacomo Picalupo y al maestro Salvatore Cormasí Zerdo como sus fiadores.. (en la que) se obligan a executar y fabricar toda la obra que se necesitare de mármoles y mizco tramizco para un tabernáculo» que se hace en Palermo de orden del Mejorada «con las calidades y condiciones que en dicha escritura se expresan»... se guarden y excuten las calidades siguientes»:

«que los cuatro frontales o palios como los llaman en Sicilia han de ser todos iguales así en el tamaño, como en la materia y la forma en cada uno se ha de representar al glorioso San Fausto, un Jardin hermoso en perspectiva según y cómo se diere entender por Joseph Diamante arquitecto y superintendente de dicha obra»

"Que se les ha de ir dando satisfacción a los suso dhos conforme fuesen trabajando y según los precios condicionados en la dha escritura no se les ha de pagar hasta tanto que la tengan fenecida concluida y entregada a satisfacción y aprobación del dho Joseph Diamante y del dicho Agustín Verstigui»

«Y con las dhas condiciones y cada una de ellas como va referido el dicho señor otorgante aprueba y ratifica la dha escritura sus cláusulas y condiciones y se obliga con sus bienes.... Y así lo otorgó y firmo. Marqués de Mejorada. Ante mi Juan Bauptista Munilla.» ${ }^{39}$.

En otra de las escrituras el Marqués de Mejorada expone, como en las anteriores, que la otorgada en Palermo a primeros de septiembre ante el notario Furino por Agustín Verstigui en su nombre "y de la otra-parte-Carlos Faulisi y Piscatore Guicillerio artífices de obra de lapizlazolo en que se obligan los dhos. a executar en el term ${ }^{\circ}$ de diez meses toda la obra que se necesitare de lapizlazolo para un tabernáculo que de orden del señor otorgante se está ejecutando en el dho Reyno de Sicilia para el Glorioso San Fausto confesor según se contiene en los diseños que a este fin ha executado Joseph Diamante arquitecto de dicho Reyno de Sicilia y han comunicado a los dhos artífices por medio del dho don Agustín de Verstigui en

38 APM, Protocolo n. ${ }^{\circ} 13337$, f. $^{\circ} \mathrm{s} 404-404$ v. ${ }^{\mathrm{a}}$

39 APM, Protocolo n. ${ }^{\circ} 13337$, f. $^{\circ}$ s $400-400$ v. ${ }^{a}$. 
precio de quinientas onzas moneda corriente de dho Reino..» La aprueba y ratifica su contenido en Madrid ante Munilla el 20 de octubre de 1692 escribiendo las siguientes condiciones en las que se ha contratado la obra:

"Que los dhos artifices han de cumplir con todo lo que en dha escritura se contiene $y$ al plaço en que en ella se expresa executandola con todo el primor que en ella se previene y a satisfacción. De Joseph Diamante ajustándose enteramente a las medidas y tamaños de dhos diseños sin que por razón de dha obra hayan de poder pedir.. más cantidad.. La cual.. Se les ha de ir pagando según lo fuesen trabajando.. Y no se les ha de acabar de dar satisfacción hasta tanto la avran acabado...»El Marqués repite que aprueba y ratifica la escritura y sus cláusulas y se obliga con sus bienes firmando con su nombre ante el notario Munilla el 20 octubre $1692{ }^{40}$.

La última de las escrituras a las que se refiere el primer documento que se ha comentado menciona, como siempre, que en Madrid de a 20 de octubre de 1692 «ante escribano y testigos Sr. D. Pedro Cayetano Fernández del Campo Angulo y Velasco comendador de la Peralada en la dha Orden y caballería de Alcantara Marqués de Mejorada y de la Breña y dixo que en la ciudad de Palermo en primero de septiembre pasado de este presente año ante Joseph Furino notario palermitano se otorgó escritura de la una parte don Agustín de Verstigui Egora oficial de Estado y Guerra del Rey de Sicilia en nombre del Sr. Otorgante y de la otra Andrea Ateymingari, Juan Antonio Gerardo y Caetano Cignorelli.. de mancomun .. como principales y Franco Gargan como su fiador, todos plateros en dha ciudad de Palermo por la cual se obligaron a executar y fabricar y elaborar toda la obra que se necesitare para un tabernáculo que al Glorioso San Fausto confesor se está fabricando đë orden del dho el Sr. Otorgante en dha ciudad de Palermo, y los dhos artífices se obligaron a executar toda la obra que como se ha dicho se necesitare así de bronces dorados como en Sicilia se llama rami de oerati (sic?) según y en la forma que en dicha escritura se expresa por precio de a ochocientas y treinta onzas de moneda de Sicilia que se les ha de ir pagando. Conforme fuera trabajando como se expresa.. en la dicha escritura y sus cláusulas.. A que el señor otorgante se remite y da aquí por insertada. cláusulas y condiciones con las limitaciones siguientes:»

"Que los dhos artífices estén y queden enteramente obligados a lo que en dicha escritura contiene y les toca por su parte»

«Que no han de poder pedir.. más cantidad que las dichas ochocientas y treinta onzas ni por raçón de Ramo ni de oro ni hechura modelos ni otra alguna.. demasía..»

"Que se les ha de ir pagando.. Conforme fuesen travajando..»

$\mathrm{Y}$ con estas condiciones el otorgante ratifica y aprueba la escritura, siendo testigos D. Juan Piñera Manrique, D. Pedro Cabeças y D. Juan Bauptista de Arrantia ${ }^{41}$.

Aunque como se advierte claramente en su lectura, las escrituras reflejan en síntesis las otorgadas en Sicilia para su mera ratificación por el Marqués de Mejorada, y sin duda las originales serán más completas, proporcionan los datos precisos para documentar esta obra típica de la técnica del intarsio de materiales polícromos que o bien consiste en una base marmórea en la que se excavan alveolos de la forma precisada en un diseño que se recubren con las correspondientes piedras coloreadas o sobre un fondo común, como una especie de mosaico, se ajustan los componentes polícromos recortados.

40 APM, Protocolo n. ${ }^{\circ} 13337$, f. ${ }^{\circ}$ s 399-399 v. ${ }^{\text {a }}$.

${ }^{41}$ APM, Protocolo n. ${ }^{\circ} 13337$, f. $^{\circ} \mathrm{s} 403-403 \mathrm{v} .^{a}$. 


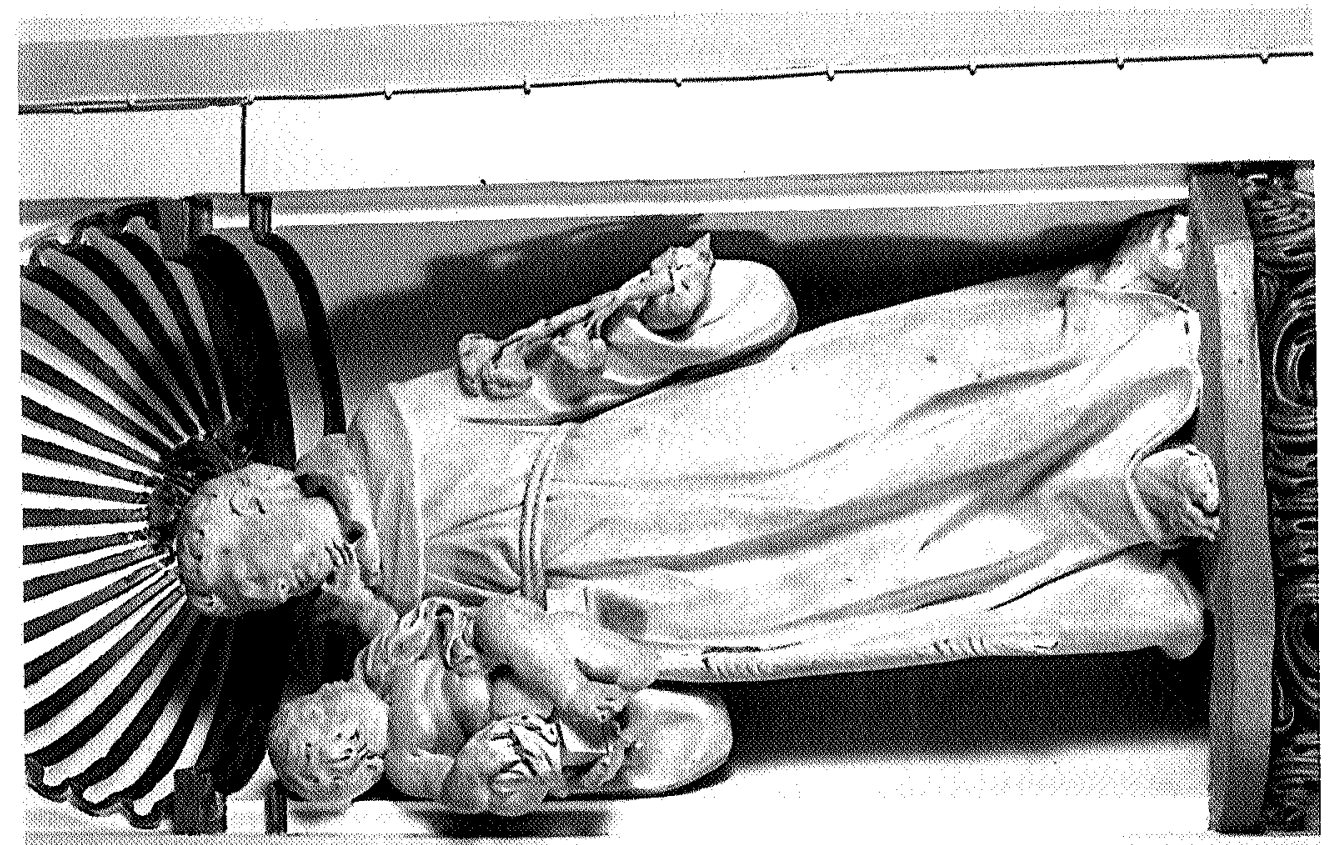

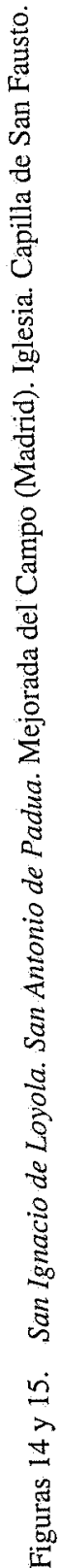


Este proceso o esecuzione del commesso, en palabras italianas, exigía ricos y costosos materiales y expertos oficiales en su tratamiento tanto la preparación de los mármoles en delgadísimas láminas, como su acabado final para conseguir la brillantez de color perseguida.

La obra se encomienda a la vigilancia de un Superintendente y Director, Joseph Diamante, que proporciona a los artífices sus diseños y medidas. Sorprende la pobre cantidad que se le asigna «como gratificación» por su trabajo, 60 onzas, si se la compara con la que se destina a los otros artistas. No se ha localizado su nombre en los diccionarios más comunes de artistas ni en la bibliografía sobre el tema muy escasa y de difícil acceso en España. Por ello en principio se dudó fuera autor de los diseños originales o meramente su intérprete pero sus títulos de arquitecto y pintor apuntan claramente a ser de su responsabilidad el proyecto total del Baldaquino, los llamados paliotto en Italia a lo que se refiere los documentos españoles cuando aclaran que se llaman en Sicilia palios.

El contrato con Joseph Ragusa, maestro marmolista como principal que presenta como a sus fiadores a Jacomo Picalupo y al maestro Salvatore Comarsizerdo (sic) precisa la estructura del Baldaquino y las motivos decorativos que presidirán sus frentes: determina que los cuatro frontales o palios serán iguales en tamaño y materia y representarán en ellos a San Fausto «en un Jardín hermoso en perspectiva» según acuerdo de Joseph Diamante y que se les irá pagando-no fija en este caso la cantidad-conforme vayan haciendo la obra. Estos frentes en la actualidad tres pues el cuarto, perdido, se reemplazó recientemente, son muy bellos y representan al Santo en un jardín pero en distintas composiciones.

La disposición rectangular de los frentes se estructura en tres espacios bajo arcos ricamente decorados sostenidos por columnas torsas que dejan ver, en los laterales de dos de ellos, los nervios de la cúpula que los cubre, centrados por preciosa fuentes tras los cuales en pếspectiva y sobre un fondo azul árboles. El espacio central se dedica en los tres conservados a la representación del Santo que vestido de monje se ocupa en una de las escenas en ajustar sobre alto zócalo un enrejado de madera, apareciendo en otra cavando en el jardín rodeado de baja balaustrada de perfil mixtilíneo en tanto que en la tercera escena se le representa en oración arrodillado sobre los parterres del jardín acotado en este caso por un frente recto de balaustrada baja que deja ver el fondo «en perspectiva» que exigía el contrato (Figs. 7, 8 y 9).

Sobre esta base se yergue la especie de pirámide escalonada compuesta de cuerpos en forma de urna que decoran sus frentes con galones dorados y azules rematada por el templete sostenido por «arpías» de bronce dorado y coronado por la figura del Santo en este mismo material de las que se hablará (Figs. 12 y 13).

En este caso el nombre del maestro marmolista Joseph Ragusa parece que puede relacionarse con los de un Giacomo Ragusa, escultor localizado en Roma en 1626 y cuya actividad se desarrolla en Palermo y más aún con el Giambattista Ragusa, natural de Palermo, fallecido el año de 1727 que, como el anterior formado en Roma, interviene en las mejores obras palermitanas de su especialidad sean la fachada de su Catedral, la Casa Profesa, las esculturas de San Francisco de Paula o la Inmaculada del monumento de la Plaza de Santo Domingo, según modelo de Bernini y sobre todo en este caso, su paliotto en la Catedral de Palermo reallizado,con decorazione a mischio e a tramischio, o en relieve, aunque de estilo distinto a lo de Mejorada. No se ha encontrado más referencias al artista en la escasa bibliografía localizada sobre el tema aunque el nombre del Ragozzino dado por Ruotolo recuerda al de Mejorada ${ }^{42}$.

42 Thieme, U. und Becker, F.: Allgemeines Lexikon der bildenden Künstler. Leipzig.- Ruotolo, R.: «Momenti dell' arte del marmo napoletano: opere e artifici degli anni novanta del seicento», Ricerche sul 600'napoletano, 1990, pp. 207-215.- Ruggieri Tricoli, M. C.: Il Teatro e l'Altare. Paliotti «d'Architettura» in Sicilia. 


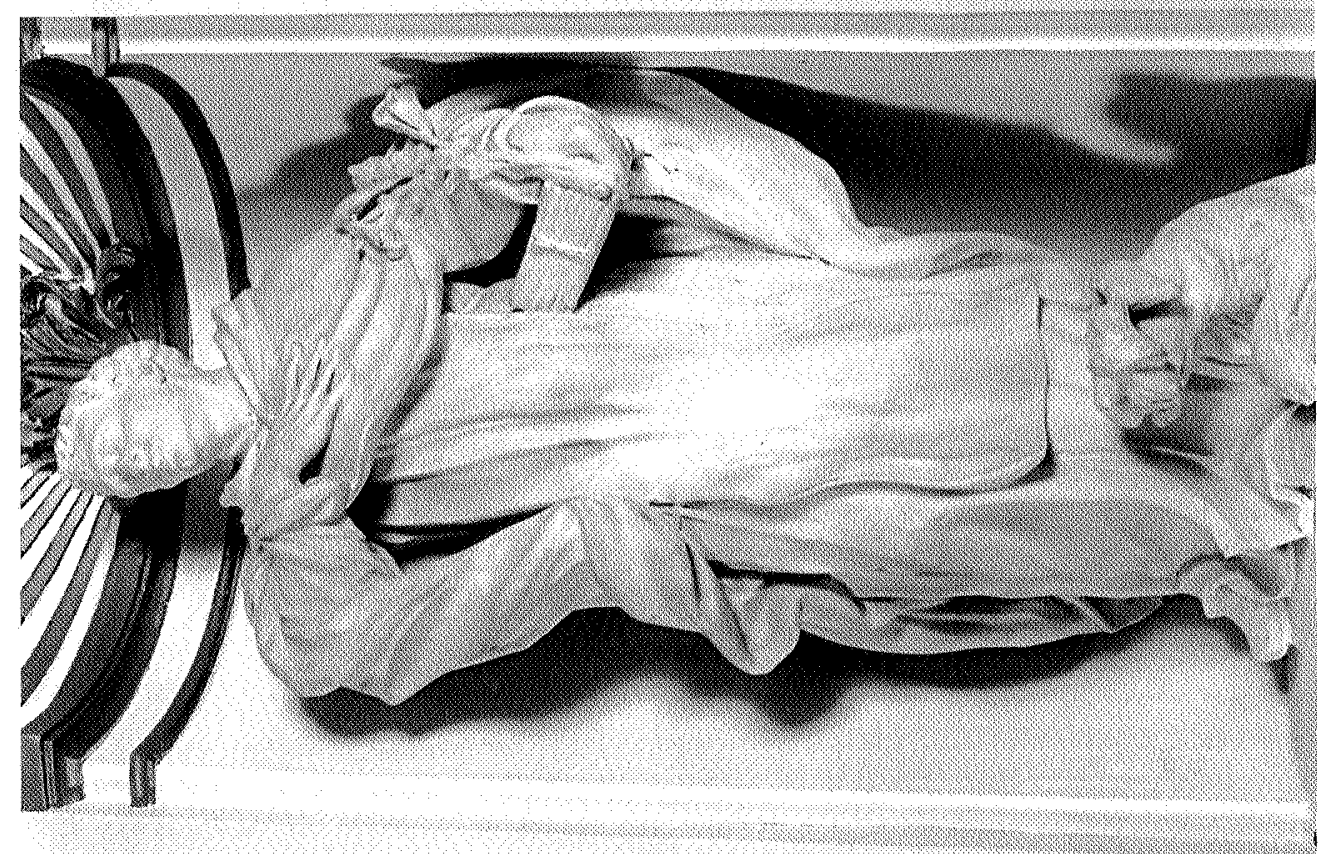



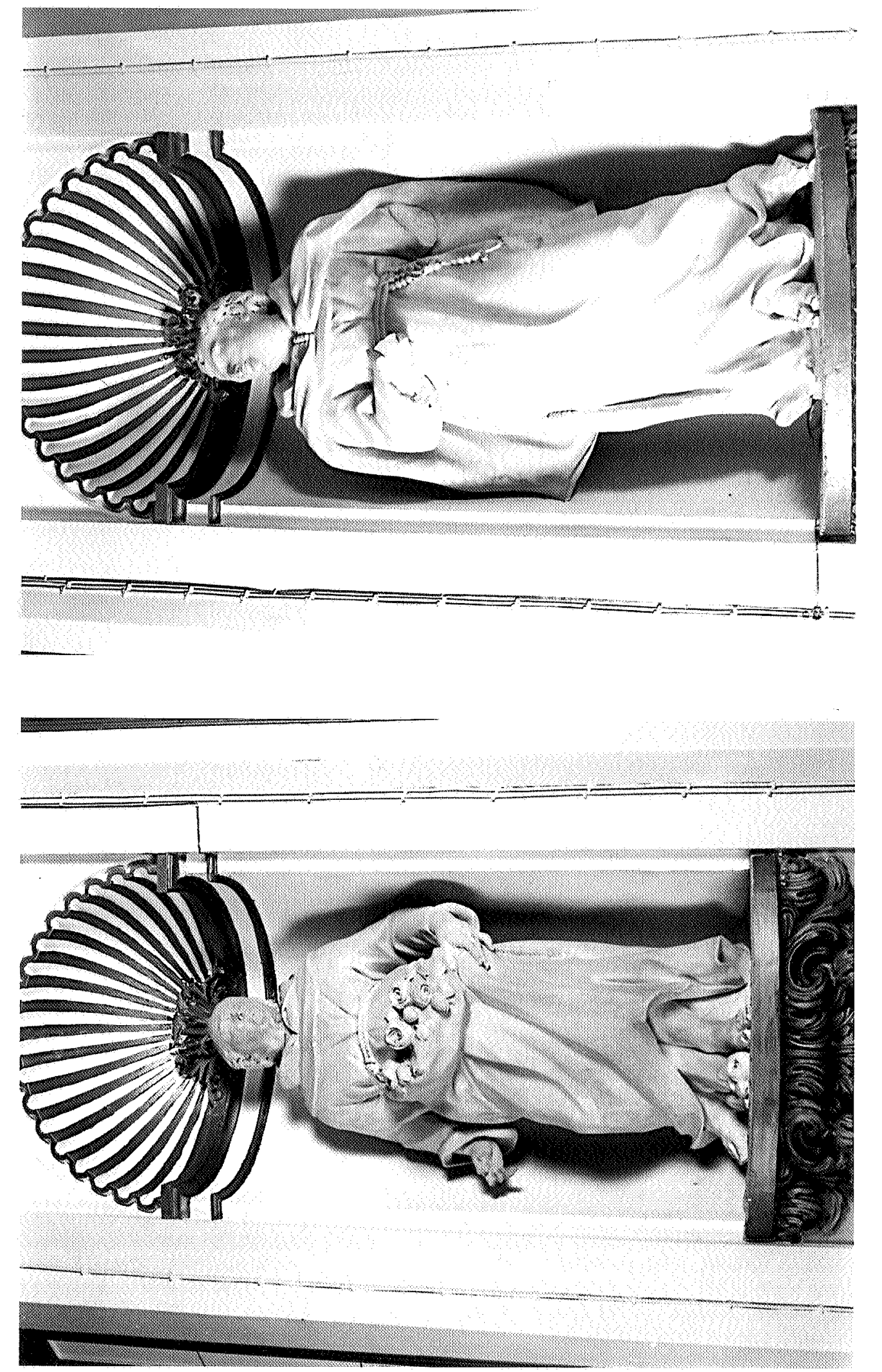

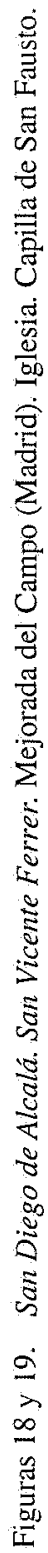


Sobre la técnica empleada recuerda aquí a la descrita por María Celia Galassi en obras genovesas con la variante de la aplicación de lapizlázuli y de láminas finísimas - perdidas muchas en el Baldaquino de Mejorada - pegadas sobre una base de arcilla-blanca en el caso español. No aportó datos el específico trabajo de Helen Hillis sobre la decoración a marmi mischi en Palermo, técnica en la que era experto Ragusa según parece por contrato con él suscrito, pero proporciona una visión clara de la práctica de este tipo de obras en Palermo en tanto que las sabias indicaciones del profesor Ruotolo nos aclararon muchos conceptos sobre este campo de los marmorari napolitanos por estos años finales del siglo XVII. El espléndido trabajo que nos proporcionó sobre las Paliotti d'architettura en Sicilia, aclara muchas de nuestras dudas sobre esta espléndida obra ${ }^{43}$.

Precisamente el trabajo complementario de aplicación del lapizlázuli se encomienda a otro equipo formado por Carlos Faulisi y Piscatore Guicillerio artífices de la obra de lapizlazolo que por diseños de Joseph Diamante realizan la obra por quinientas onzas. Como se ha dicho las finísimas láminas del material, perdidos en parte, siguen luciendo la habilidad de estos artistas en la matización de los distintos tonos de azul al fondo de las escenas representadas en los frontales de la base y en los gallones de los cuerpos del Baldaquino.

La preciosa obra de bronce se encomienda a los plateros Ateimingari, Juan Antonio Gerardo y Caetano Cignorelli, avalados por el también platero Francisco Gargán. No se especifica bien su labor pero se aclara que realizaran lo que se precise así de bronces dorados o como en Sicilia se llama Rami de Orati (sic en la escritura)... por el precio del ochocientas treinta onzas, el precio más alto estipulado con los distintos artistas, con la excepción del asignado a Ragusa que no se determina. Como siempre se ajustarán a lo estipulado insistiendo en que no podrán reclamar demasías y en este caso no se menciona la dirección de Diamante.

Las finísimas figuras femeninas que sostienen el templete con colas de sirenas pero con alas, sin duda Las arpías mencionadas en el último documento sobre el Baldaquino que se citará más adelante, recuerdan en su factura el arte Toscano de por eso estos años pero dado que se han localizado los artistas que las realizan en Palermo aunque no se sabe nada de ellos no se puede sugerir nada al respecto salvo la difusión normal de la obra de las escuelas más progresivas en este campo. De hecho, en Génova, se realizan obras similares como complemento de ricos altares de mármoles intarsiati como el de San Siro revisado por Puget aunque no debió ser tan común en Sicilia ${ }^{44}$.

En su conjunto la obra es similar a obras sicilianas de la época aunque difiere en su estructura, quizás derivada de otras escuelas pues por ejemplo en las genovesas abundan altares cuyo cuerpo principal se constituye en forma de urnas, bien es verdad que más ricos y de diferentes perfiles.

\footnotetext{
Contributi tematici di Gaetano Bongiovanni, Enzo Brai, Elvira d'Amico, Sebastiano di Bebla, Cosimo Filizzola e Carolina Laezza, Lina Novara. Faccoltá d'Architettura di Palermo e Centre Ricerche Iconografiche. Palermo, Ediz. Grifo, 1992, p. 121: Giovan Battista Ragusa. Paliotto en la Capilla de San Francisco de Paula, Palermo, Catedral.-Troisi, S.: (Fotografie si Sancho Scalia) «La decorazione a mischio dell'abside di Casa Profesa». Kalós. Arte en Sicilia, VII, nov.-dic. 1995, pp. 22-29.

${ }^{43}$ Galassi, M. C., Parma Armani, E. y ...: «Artisti e artigiani del Cinquecento al Seciento: Organizazzione e funzione delle Botteghe», La Scultura a Genova e in Liguria, II, Casa dil Risparmio de Génova, 1988, pp. 47 y ss.- Hillis, H.: «Centri e periferie: decorazione ecclesiastiche in marmi intarsiati nella Palermo del XVII secolo», Arte Cristiano, nov.-dic., 1996, pp. 405-419.- Palermo, F.: «La scultura per la macchina d'altare», Scultura a Génova, vid. supra, p. 107 y s.- Civiltá del Seicento a Napoli. Napoli, Electa, 1984 (Sopraintendenza per il Beni Artistici e Storice di Napoli).- Vid. además nota 42: Ruggieri, Ruotolo y Troisi.

44 Scultura a Génova, cit. nota 43, p. 118.
} 


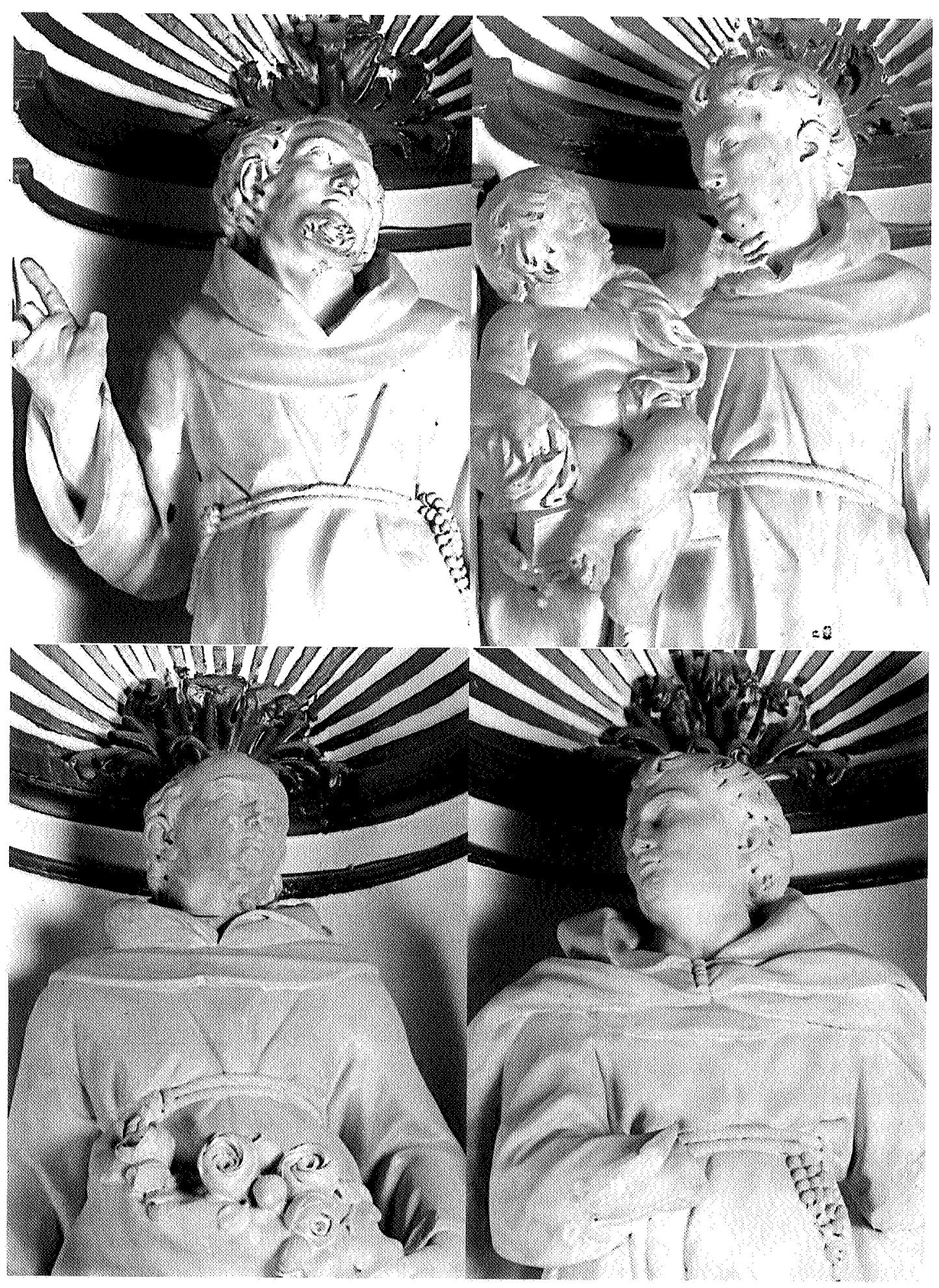

Figuras 20-23. San Pedro de Alcántara, (Detalle). San Antonio de Pádua, (Detalle). San Diego de Alcalá (Detalle). San Vicente Ferrer (Detalle), Mejorada del Campo (Madrid). Iglesia. Capilla de San Fausto. 
La figura de San Fausto, mucho más tosca hasta hacer pensar en una pésima restauración, preside este Baldaquino realizado para conservar su cuerpo, sin duda uno de los tres de los que habla el segundo Marqués de Mejorada el año de 1685. Se le representa con hábito cubierto por capa y una gran cadena al cuello y grillete de forma diferente a como aparece en los frontales del Baldaquino, con un sencillo hábito y sin otro símbolo. También lleva un libro bajo su brazo derecho y le acompaña un ángel que sostiene una vara.

El problema de esta iconografía no se ha resuelto pues el Marqués, en sus Disposiciones testamentarias, dice que dedica la Capilla de San Fausto de Mejorada al San Fausto de Bujanda (Alava) pero como el cuerpo de este Santo se conserva en este lugar, consiguió otro cuerpo de un San Fausto, pensamos que el venerado con San Plácido, San Eutiquio y otros santos en Palermo, inmortalizado por los pinceles del Correggio. De ninguno de los dos hemos localizados sus correspondientes biografías y símbolos distintitivos pero es posible que el San Fausto de los Frontales represente al Santo Labrador de Bujanda respondiendo el San Fausto en bronce al santo palermitano, Mártir, que en la Iglesia de $\mathrm{N} .{ }^{a} \mathrm{Sr}^{\mathrm{a}}$ de Valverde en Imola (Italia) se representa yacente con un angel a los pies. También se ha planteado la duda de si las escenas de los frontales, construyendo o $¿$ deshaciendo? un enrejado, plantando ¿flores? en un jardín y en oración se corresponden a secuencias de la vida del santo o pueden tener un carácter simbólico.Las pinturas que el Marqués encargó a Nápoles representaban escenas de San Fausto Labrador, pero como se dirá, se han perdido ${ }^{45}$.

Sin relación con los documentos reseñados, años más tarde, se localizó una última escritura que refiere el envío a España del Baldaquino, por su descripción, aún más rico de elementos de los que se conservan ${ }^{46}$.

En Madrid, a 20 de abril de 1695, de El Marqués de Mejorada refiere que en Palermo ha hecho edificar un Tabernáculo o retablo con un Sagrario y Arca para el Santísimo Sacramento para su Capilla de San Fausto en la Villa de Mejorada. Explica que es obra de mármoles y jaspes embutidos con algunos «pedazos de de lapizlázuli y que en el arca para al Santísimo Sacramento que es de bronce dorado han de venir algunas labores de coral», elemento que no se conserva. Sigue diciendo que el Tabernáculo se embarcó en diferentes cajones «en una ttarttana (sic) nombrada la Virgen del Carmen, San Pedro y San Pablo» en la que era patrón Leonardo Ripullina, de «ttermines» en la que viene la obra al cuidado del alférez Felipe Antonio Laínez que la entregará en Alicante a don Antonio Capurro. A Laínez se la entregará en Palermo Agustín de Ebistuegui (así el apellido en este documento) Egora que acompaña la lista de lo contenido en cada cajón. "Separadamente llega el telar de hierro sobre que viene la urna y de que se compone dicho tabernáculo», pieza que parece aludir a un armazón del monumento. Leyendo las distintas piezas contenidas en los cajones se advierte que se han perdido muchas de las que componían el tabernáculo, algunas mencionadas por Ponz como las figuras de bronce de «putti» pequeños y grandes, la citada Arca del Sacramento, una águilas y otras de menos importancia pues en su conjunto se ha conservado la estructura esencial que lo constituia. Se habla de los «miscos trasmisços», sin duda refiriéndose a los mármoles «Mischi» y los «tramischi» en relieve, en la primera, segunda y tercera escalonada

45 APM, Protocolo n. ${ }^{\circ}$ 15007, cit. nota 21, f. ${ }^{\circ}$ 556-557.- Reau, L.: Iconographie de l'art chrétien. Paris, Presse Universitaire, 1955-1959, 3 t. en 5 cols.-Bibliotheca Sanctorum, Istituto Giovanni XXIII, Roma, 19611969, I-XII (reproduce el cuadro del Correggio).- Lexikon der Christlichen Ikonographie. Herausgegeben von Engelbert Kirschbaum, S. J.: Rom-Basel, 1968-1976, 1-8. - Enciclopedia Universal Ilustrada Europea Americana. Espasa-Calpe, Madrid. Reproduce la estatua yacente de San Fausto mártir de la Iglesia de Valverde en Imola (Italia).

46 APM, Protocolo n. ${ }^{\circ} 13338$, Munilla, f. ${ }^{\circ}$ s $549-550$ v. ${ }^{a}$. 
y de las cajas que contienen los mármoles «con sus gallones de bronces dorado y estrias de lapizlázuli» que se asientan en aquellas, tal y como aparece ahora. Se menciona la «tierra de Paragon» - mármol negro- para el pedestal que no se conservan, las piezas del pedestal del santo, los citados puttinos y cabezitas de Serafines. Describe por supuesto y en primer lugar los cuatro frontales, los cuatro candelabros de mármol, los escudos, todas piezas conservadas junto a las figurillas femeninas de bronce que denomina «arpías» la figura del Santo «con un libro, grillete y soclo i pedestal de ramo de bronce dorado». Se detienen en la descripción de «El Arca de Coral y Ramo de bronce dorado para el Santísimo Sacramento», perdida como se ha dicho.

El Marqués suscribe el documento con una declaración de la finalidad de esta obra que es únicamente «un retablo con Sagrario para el Santísimo Sacramento» para su Capilla de Mejorada y que no servirá para otra cosa, con insistencia extraña que nos habla bien de un control comercial o de tipo religioso y que no tiene en principio explicación pues el baldaquino era para la capilla de San Fausto y sin duda destinado a contener sus reliquias, como de hecho aseguró Ponz al aclarar que el Arca guardaba el cuerpo del Santo.

En el Baldaquino hay dos espacios vacíos, entre las cuatro arpías uno y el segundo sobre un cuerpo pequeño como los tres inferiores de las «escalonadas», entre cuatro pilares pero la documentación consultada sólo habla de un Arca, la citada por Ponz sostenida por figuras de bronce que en principio pensamos que es la misma destinada a Sagrario según el documento de envío de la obra que no menciona ningún otro receptáculo para contener reliquias. Quizá hubo un arreglo a la llegada de la obra y se guardó el cuerpo de San Fausto en el Arca instalando en el primer cuerpo de la «escalonada» y en cada uno de sus frentes pequeños Sagrarios enmarcados en mármol.

La descripción confirma lo expuesto referente a la distinta estructura de este Altar-Baldaquino de la usual en lo siciliano, más próxima a la que presentan algunas obras genovesas. La riqueza de elementos de bronce, la disposición en urnas de frentes convexos escalonadas y el conjunto diferencia esta obra de lo que se ha visto quizás por no conocerse la obra del taller siciliano al que se le encargó, pero no obstante, como se dice en las Disposiciones testamentarias del Marqués que se comentarán más adelante la traza vino de allí.

Una vez conocidos autores, cronología y circunstancias de la llegada a España de este magnífico tabernáculo se ha podido también determinar la escuela siciliana a la que pueden adscribirse sus magníficos frontales gracias al magnífico estudio de los «Paliotti d'architettura» sicilianos que nos fue proporcionado gentilmente por el profesor Ruotolo ${ }^{47}$.

La lectura de este trabajo nos sumergió en el mundo fantástico de esta típica producción artística siciliana que tiene su momento de mayor esplendor hacia los años de 1680-1750.El frontal, o «Palio y paliotto» en el vocabulario italiano, es uno de los elementos más importantes de la estructura arquitectónica del Altar y su gran número ha permitido su catalogación tipológica, iconográfica y decorativa. La época barroca con el gusto por lo escenográfico multiplica sus ejemplares, de forma más ostensible en Sicilia pues ésta «pequeña arquitectura», verdaderos «modelos», facilita la figuración simbólica tan exaltada en este mundo barroco en el que en muchos de sus aspectos interviene muy definitivamente el espíritu de la Contrarreforma representado por las Ordenes religiosas, singularmente la de la Compañía de Jesús.

Sin insistir en estos aspectos estudiados en profundidad en el mencionado estudio, reducimos nuestro análisis comparativo a los meros aspectos formales como el de la insistente

${ }^{47}$ Ruggieri, cit. nota 42. 
presencia en estos «Paliotti» de ciertos elementos arquitectónicos, como el belvedere, asociado al pórtico, las columnas torsas o el jardín.

Uno de los Apartados del citado trabajo se dedica al estudio de los «Paliotti in marmo e pietre dure» pues estos frontales o Paliotti escenográficos fueron realizados en muchos casos con la citada técnica de la «Tarsia marmórea» heredada de la tradicional florentina. La técnica siciliana surgió bajo la doble influencia florentina y romana mediatizada por Nápoles de hecho inspirada por Cósimo Fanzago años más tarde a través de la obra del Serpotta en Sicilia ${ }^{48}$.

El paliotto «prospéttico» se relaciona con la técnica escenográfica y entre los distintos tipos de estos frontales destacan los que representan un Pórtico de «profundidad prospéttico» o como dice, en otros casos «con pórticos a plat», en que los efectos de la perspectiva no alejan tanto el fondo al espectador. Al primer tipo pertenecen los frontales de Mejorada que recuerdan mucho en los detalles de su escultura, arcos con columnas torsas, guirnaldas, etc, al realizado según diseño del arquitecto Paolo Amato por el marmolista B. Pampillonia para la capilla «Libera Inferni» en la Catedral de Palermo, hoy en Gibilmanna encargado en 1684 precisamente por el Obispo español Palafox (Fig. 10).

Salvo pequeñas diferencias en la base de los floreros, las balaustradas al fondo, las sicilianas rectas, y sobre todo las deliciosas escenas de jardín con San Fausto que aparecen en Mejorada, el parecido permite adscribir estos frontales sicilianos conservados en España al círculo próximo del taller que llevó a cabo el citado frontal de la catedral de Palermo, aunque, por los documentos, independientemente de él pues los artistas citados en las escrituras españolas indican una organización artística completa con su director, el arquitecto y pintor Joseph Diamante, sus trabajadores de lapizlázuli, su marmolista e incluso los plateros encargados de los complementos de bronces dorados ${ }^{49}$.

\section{La obra de escultura en mármol encargada a Génova por el segundo Marqués de Mejorada}

Como ya Ponz describió, la Capilla presenta en nichos instalados en los machones que sostienen los cuatro arcos sobre los que descansa la cúpula, ocho figuras - ahora sólo quedan seis- dos en cada muro, una en la parte superior y otra en la inferior. Las que aparecían en los nichos superiores eran: San Antonio de Padua, San Francisco de Asís, que falta, San Diego de Alcalá y San Pedro de Alcántara en tanto que en los inferiores se situaban San Vicente Ferrer, San Ignacio de Loyola, San Francisco Javier, perdido y Santo Domingo de Guzmán, descabezados los tres de los nichos inferiores en la Guerra de 1936 que se les repusieron en la restauración (Figs. 14-23). Las figuras realizadas en blanco mármol, quizás algo menos brillante y más poroso que el de Carrara, aparecen a primera vista como obras propias del ambiente cultural napolitano de Cósimo Fanzago, cuyos modelos inspiran claramente algunas figuras de Mejorada, así el San Antonio de Padua, de composición y aspecto muy parecido al que el gran artista realiza en bronce para la Capilla del Tesoro de San Jenaro en la Catedral de Nápoles pero aunque en conjunto recordaban las obras de sus discípulos como

\footnotetext{
48 «Tipología architettoniche nei Paliotti in marmo e pietre dure» en Ruggieri, cit. nota 42, pp. 105-132.Vid. también nota 42, Troisi.

${ }_{49}$ Paliotto del Amato en Ruggieri, cit. nota 42, p. 112; el reproducido en p. 117 de la Iglesia de San Giuseppe dei Teatini, con atisbos de jardines pero en el contexto de los emblemas marianos como «Hortus Clausus»; más proximos a los representados en Mejorada; Paliotto de Santa María delle Grazie en Gioiosa Marea, p. 102 (Fig. 11). El Paliotto del Amato hoy en el Santuario de N. ${ }^{a}$ Sr. ${ }^{a}$ de Gibilmonna. El Obispo Juan de Palafox sobrino del más conocido Obispo de Osma y de Puebla de los Ángeles de su mismo nombre.
} 
las de un Lorenzo Váccaro y sobre todo las menos finas de Nicola Fumo (Fig. 24) que como ya se ha dicho trabaja de hecho para el Segundo Marqués de Mejorada, - las obras conocidas que envió a España son de madera-, el análisis comparativo no era definitivo. Se recordó entonces la noticia de la llegada de los sepulcros del Primer Marqués de Mejorada desde Génova, obra también de marmi intarsiati, a juzgar por los reparos que se encomiendan a Carlos Gautier y por ello se continuó la búsqueda.

La primera noticia que confirmaba nuestra idea de que las obras en mármol encargadas por el Marqués se hicieron en Génova la proporcionó un documento que dio a conocer, escuetamente, Teresa Baratech, sobre el retablo en mármol encargado al arquitecto milanés Francisco Abril y la segunda, más directamente relacionada con las obras conservadas, se localizó en la Memoria que contiene las Disposiciones testamentarias de Pedro Cayetano Fernández del Campo en la que concretamente se refiere a las ocho esculturas de mármol de los nichos encargadas en Génova, aclarando además, que el retablo de Francisco Abril no pudo hacerse por la muerte de este artista, lo que explica que Ponz no lo mencionara ${ }^{50}$.

En relación a la primera noticia sobre èl retablo, no obstante no haberse realizado, interesa conocer sus claúsulas aunque sea en síntesis pues describen una obra genovesa al detalle, incluidos los materiales a emplear y su estructura, muy similar a juzgar por el documento, al que, conservado, se encarga a Génova para la Iglesia de Santo Domingo de Cádiz, obra de Andrea Andreoli con esculturas de Esteban Frucos ${ }^{51}$.

El documento fechado el 2 de septiembre de 1691 estipula que Don Pedro Cayetano Fernández del Campo de una parte y de la otra Francisco Abril arquitecto milanés, hixo del difunto Andrés Abril se conciertan para que éste artista realize un retablo de jaspés $\hat{s}^{3}$ piedras, personalmente, siguiendo el dibujo que ambas partes poseen, para la Capilla Mayor de la Iglesia de su Patronato en Mejorada.Se determina que sus columnas sean salomónicas..de piedra de Portobenere que según demuestra la planta o dibuxo es de color negro con bettas doradas con dos nichos para San Francisco y Santa Inés. El friso ha de ser de embutidos de piedra de jaspe vaxo de Francia con calados blancos También determina que donde se coloquen los escudos por detrás dellos se ha de llenar toda la buelta de Piedra Bardilla ¿bardiglia? La decoración escultórica debía ser muy importante y se describe con pormenor:Que el San Francisco y Santa Inés han de ser estatuas enteras de todo relieve y otrosi la de los Ángeles, el Santo Cristo, San Juan y Santa María han de ser de más de medio relieve y Ntra. S de la Asumpción con los Ángeles no ha de ser de inferior hechura......ni de menos obra y figuras que las que el representa y su guarnizion a de ser de una pieza y Christo San Juan y María también con su guarnizion y de una pieza. Tendrá también otros quatro Santos que están en los quatro pedestales de dha planta o dibuxo han de ser de medio relieve y los otros quatro medios cuerpos de Santos: San Buena Bentura, San Geronimo, Santo Domingo y Santiago han de ser de medio relieve.

50 APM, Protocolo n. ${ }^{\circ}$ 13337, J. B. Munilla, f. ${ }^{\circ}$ s 206-209 (Dio noticia escueta del documento Baractech Zalama, T.: Catálogo de Documentos, Comunidad de Madrid, 1998, n. ${ }^{\circ}$ 1224).- APM, Protocolo n. ${ }^{\circ} 15007$, cit. nota 21, f. ${ }^{\circ}$ s 582-588 v. ${ }^{\text {a: }}$ incluye en las notas al margen sobre la obra en la Capilla Mayor y en la de San Fausto lo que se va haciendo; en los f. ${ }^{\circ} 584 \mathrm{v}^{\mathrm{a}}$ y 585 , menciona las ocho estatuas y en los f. ${ }^{\circ}$ s 588 y $588 \mathrm{v} .^{\mathrm{a}}$, se refiere al contrato del retablo, que no llegó a realizarse por la muerte de Abril, como se comentará. Sobre el ambiente cultural napolitano, Vid., Civiltá, cit. nota 43, Ponz, cit. nota 33.

${ }_{51}$ Scultura a Génova, cit. nota 43, f. ${ }^{\circ} 226$.- Díaz, V.: Dos breves artículos en el Diario de Cádiz (6-101990 y 9-12-1990) que divulgan noticias documentales y reproducen la firma de Frucos en el retablo de Santo Domingo y en el de San Pablo de la Catedral de Cádiz (Fig. 25). 


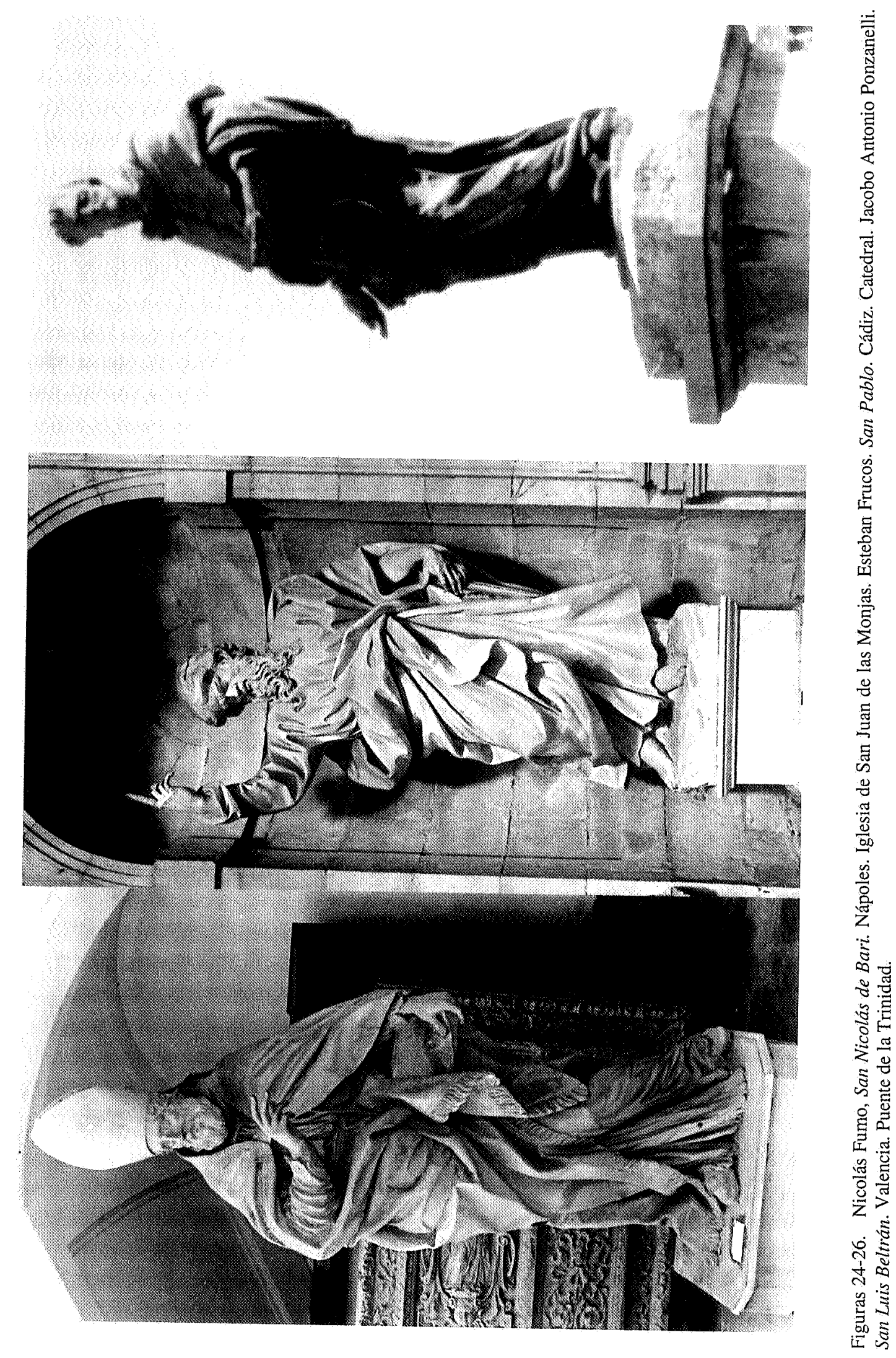


El frontal será «follajeado» y las dos Bichas questan arrimadas al Santo Cristo han de ser de más de medio relieve de marmol blanco ..... La custodia ha de ser de marmol blanco y embutidos de piedras de diferentes colores como son marmol roxo de Francia.. Piedra Berde de Ponservera -....- y de Alabastro Benado de Zestere y ha de llevar quatro columnas con sus guarniciones y remates con su cornisa alrededor y enzima... un remate de una media naranja calada de follaxe .. embutida de colores .

El dho Franco Abrill en la forma que va referida y según. lo demuestra dha planta o dibuxo se obliga a hazer y executar dha obra y retablo ..... y con la diferencia de piedras que van declaradas y hazerle... tan vien ... como otras obras que ha hecho.. dentro de un año que ha de empezar. el día que se le entregue el dinero.... y la pondra libre a su señoría de todo gasto ... y demás lizencias para su seguridad en qualquiera Puente que se le pidiera de la ciudad de Genova ............ y de otra Persona en su nombre para que le remita dha obra y retablo con que enbiara un Mozo y un Oficial de dho exercicio para asentarle en la dha Capilla Mayor a quien el Dho Marqés ha de pagar la costa de viaxe de yda buelta y estadia conforme fuese estilo de dha ciudad de Genoba y como se hubiere hecho con otros que han venido a España....El dho Sr. Marqs se obliga a que luego que dicho oficial y mozo ayan asentado en dicha capilla mayor el dho retablo les acavara de satisfazer el coste .. según costumbre de dha ciudad de Génova o se haya hecho ... con los que han venido a España a dho ministerio....Asimismo a q puesta dha obra libre y sin gasto alguno.. en el Puerto de qualqra Puente de dha ciudad de Genova .. pagara por ella .. al dho Frco Abril o a quien su poder hubiere tres mill rs de aocho de a cinco libras de Genoba moneda corriente cada uno o su valor de dhas cinco libras. A continuación el Abril se obliga a dar fianzas antes de empezar la obra y las partes se conciertan en las condiciones referidas ante el testigo Don Francisco Jimenez, tanto el Marqués como el maestro que con fina letra firma Francisco firmo. No nos detenemos más en la obra dado que no llegó a realizarse pero en todo caso lo transcrito puede ser útil para el estudioso de este campo.

Las disposiciones testamentarias contenidas en la Memoria que el Marqués de Mejorada lega a su esposa junto al Poder para testar ${ }^{52}$ debieron irse redactando a través de los últimos años de su vida, al menos desde 1685 como indican las anotaciones al margen del texto sobre acontecimientos reales surgidos en relación a lo redactado.

A partir del folio 582 de este voluminoso documento el segundo Marqués de Mejorada se refiere concretamente a sus obras en su villa de Mejorada del Campo y aclara muchos de los puntos confusos en relación a los sucesivos encargos artísticos a Génova y Sicilia que se conocían por los documentos comentados.

Por de pronto aclara que en Mejorada se ha ocupado tanto de la Capilla que he labrado a San Fausto Confesor con todas las alajas que pusiera en ella y en la Sacristía y en mi Capilla Maior de la que es Patrono y que ni dicha Capilla Mayor ni la de San Fausto pueden entrar en el caudal de bienes a dividir a su muerte. Es decir, que como se suponía, se había ocupado tanto de la nueva capilla dedicada a San Fausto como del arreglo de la Capilla Mayor de la Iglesia y dice que si no le da tiempo a acabar de adornarlas dejará órdenes para que se haga pues lo prometió por voto y por lo mismo sus herederos lo considerarán como una deuda (f. $583 \mathrm{v}^{\mathrm{a}}$ ). Al margen, como en otros muchos de los folios de esta Memoria, anota que la Capilla de San Fausto está terminada y que solo falta dorarla, poner un candado a la reja, que ha de comunicar con la capilla mayor y poner las losas de Génova que tiene en su casa de Mejorada (f. ${ }^{\circ}$ 584).

\footnotetext{
52 Disposiciones Testamentarias, vid. notas 21 y 50.
} 
También dispone adornar los onze nichos de la referida capilla..de pinturas las quales hize ejecutar en Naps. Y estan..pagadas. adornando cada uno con un marco ligero dorado como tengo discurrido con Matías Roman architecto y es quien asistió a la fábrica de dicha capilla. Al margen anota que ya se han colocado y que solo les faltan los marcos. Es decir que Matías Román continua al mando de las obras y que los cuadro de la Vida de San Fausto Labrador firmados en 1690 por Alberto Arnón en Nápoles, descritos por Ponz, se han perdido en la guerra de $1936^{53}$.

En el mismo f. ${ }^{\circ} 584 \mathrm{v}^{\mathrm{a}}$ y 585 habla de que ha de poner en otros ocho nichos en que solo deven ir estatuas ocho de diferentes santos de piedra las quales se estan ejecutando en Gen - la palabra está cortada pero tiene que ser Génova, por el contexto del documento- por orden del Sr Don Francisco Grillo que por hazerme merzed se ha encargado de cometerlo a sus correspondientes y según tengo entendido tienen hecha escritura de obligazion los artífizes de tenerlas entregadas en todo el mes de junio de este presente año de 1692 cada una de estas estatuas puestas en Madrid.tendra de toda costa de veynte y ocho a treinta doblones.

La anotación al margen explica que De estas ocho estatuas las seis estan en mi poder oy 29 de Nove de 1692 faltan solo dos que son las de Sn Frco de Asis y Sn Ant de Padua (Fig. 15) las quales se estan acavando y feneziendo; hasta ahora por quenta dellas no tengo satisfecho ni pagado porzion alguna porque el Sr. Grillo no me ha dado la quenta, aunque más adelante y también al margen aclara que vinieron las otras dos estatuas y pagué a D. Frco Grillo el coste de ellas por Azcutia..ya estan colocadas en sus nichos y yo con este consuelo. Sin duda las ocho esculturas que esperaba le enviaran de Génova son las que ahora se conservan - menos dos de ellas - que describiera Ponz y a las que nos hemos referido antes. No da todas las advocaciones pero cita las de San Antonio de Padua y San Francisco de Asís, ésta una de las perdidas, que con San Diego de Alcalá, San Pedro de Alcántara, San Vicente Ferrer, San Ignacio de Loyola y Santo Domingo de Guzmán aún se exhíben hoy en día en los nichos de los pilares que sostienen los arcos de la Capilla de San Fausto (Figs. 14-23). Los datos son de gran interés para la clasificación de las esculturas al proporcionar la fecha de realización y escuela a la que pertenecen como más adelante se analizará.

Después de referirse a unos bufetillos de plata de estrado donados a la misma Capilla, a partir del f. 585 se ocupa de todo los referente al Altar Baldaquino, o Tabernáculo encargado a Sicilia, último adorno que le dedica, mencionando las escrituras concertadas y su ratificación en Madrid, de las que antes se ha hablado, localizados independientemente de estas disposiciones testamentarias. También anota al margen que ya está acabado y solo proporciona algún dato más de los comentados, como el pago por hombres de negocios genoveses.

En el f. 586 v. $^{\text {a }}$ y 587 explica que dentro del arca de este tabernáculo se ha de poner el cuerpo de San Fausto mártir que tengo en mi oratorio porque aunque no es el mismo $S$ Fausto Confesor a quien yo debo este culto obsequioso cuyo cuerpo esta integro en Bujanda hallandome con un cuerpo Santo del mismo nombre debo sobstituirle, lo que como ya se ha comentado dificultó el estudio iconográfico de su representación en los frontales del altar y en la estatuilla de bronce.

También hizo voto de componer y adornar la Capilla Mayor de la Iglesia (Fig. 3) pero de forma condicionada y que encontró oposición por parte de los vecinos de su villa. Fundamentalmente, según explica a partir del f. 589 v. ${ }^{a}$ pensó en poner primero, junto a la reja que separa la Capilla Mayor del resto del desaliño de la iglesia, un retablo de madera con la pintura de la Candelaria y sustituir el retablo de madera, estatuas y pintura que tenía la Iglesia

${ }^{53}$ Ponz, cit. notas 26 y 33, p. 103.- APM, Protocolo 15007 , cit. nota 21, f. 584 v. . 
por uno de mármoles y jaspes para lo que se ha concertado con Francisco Aprile, el retablo del que se ha hablado. Aquí aclara, al márgen, en f. 589 v. ${ }^{a}$ que Murió antes que esta obra se empezare Fco Aprile architecto genoves con lo que mi intenzión es que se ejecute en Sizilia según se contiene en el diseño que vino de halla, pero debió costarle decidirse porque en otra nota al margen dice que no se haga en Sicilia si no en Génova para terminar desdiciéndose imponiendo que se haga bien en Genova bien en Sicilia, que como puede comprobarse fue su definitivas elección.

Como noticias complementarias se recuerdan sus otros donativos como dos espejos, quizás similares a los donados a Guadalupe de los que da noticia en estas páginas M. ${ }^{2}$ Paz Aguiló, o la pintura de San José, la Virgen y el Niño que parece que sustituye con la encargada a Lucas Jordán que Ponz describe como una Huida a Egipto. No tenemos noticias sobre el cuadro de Abraham y los tres Ángeles, que el Marqués dice referirse a la Santísima Trinidad y que es original de Bandeig (sic, pero será ¿Van Dyck?) y que Ponz no cita.

Ponz describió las pilillas de ágata y otras dos grandes que consideró italiana que se mencionan en el documento que comentamos decidiendo que las dos pilas grandes que están en su casa se pongan a los dos lados de la puerta ${ }^{54}$.

Este largo documento contiene otras noticias artísticas de interés como las referidas a las cuentas habidas con Thomas Aspur o con el platero Juan Morales y sobre todo las que nos presentan a Matías Román como el arquitecto del Marqués y su hombre de confianza que muere precisamente en estos años. Los últimos folios determinan sus legados hasta el último mes víspera del de su muerte, en los que ya su letra es prácticamente ilegible.

Las Disposiciones testamentarias del Marqués se cumplieron estrictamente salvo el retablo de mármol, por fuerza mayor, y en los años en que aún vivía. Proporcionó los datos que nos faltaban sobre las magníficas esculturas de mármol - aunque en la Memoriấse dice que son de piedra- No da el nombre de los artistas que las hicieron en Génova pero las fechas conocidas de su realización y la intervención de Francisco Grillo en el encargo facilitaran el camino para localizarlos algún día.

Se conocen escultores genoveses que por aquellos años trabajan para España como el citado Esteban Frucos pero su arte de figuras más achaparrados e indumentaria de plegado más afilado no recuerda el que presentan las esculturas en mármol de Mejorada.

Revisando la obra de otros artistas conocidos que pudieran haber trabajado para clientes españoles y hubieran podido tener relación con Grillo nos llamó la atención el Giacomo Antonio Ponsonelli, el Jacobo Antonio Ponzanelli de las fuentes españolas, que tantas obras envió a España. Oriundo de Carrara, nacido en 1654, muere en Génova en 1735. Casado con una hija del famoso Felipe Parodi, su actividad, muy relacionada con la de su suegro, aparece en la línea berniniana. Uno de sus retratos es precisamente el que hizo a Marcantonio Grillo hacia 1677, pensamos que familia de Don Francisco. Desde el punto de vista estilístico se recordaron su San Luis Beltrán y su Santo Tomás de Villanueva (Fig. 26), hoy en el puente de la Trinidad de Valencia, que presentan siluetas muy similares a la de los Santos de Mejorada, envueltos en sus mantos como aparecen en los de esta ciudad española. El parecido es mayor con su figura de Jesús Adolescente en la iglesia del Temple valenciana (Fig. 27) que quiebra su manto a la izquierda de forma similar a como aparece plegado el manto de Santo Domingo de Guzmán de Mejorada (Fig. 17). El tratamiento de bucles suaves terminados en rizos recuerda el del peinado de los Santos que han conservado sus cabezas originales en Mejorada y el perfil del Niño del San Antonio de Padua (Fig. 15) es parecido al de un faunillo que aparece a los pies del Tritón (Fig. 28) de la fuente instalada en los jardines Pontons de Valencia.

\footnotetext{
${ }^{54}$ Ponz, vid. nota anterior.
} 


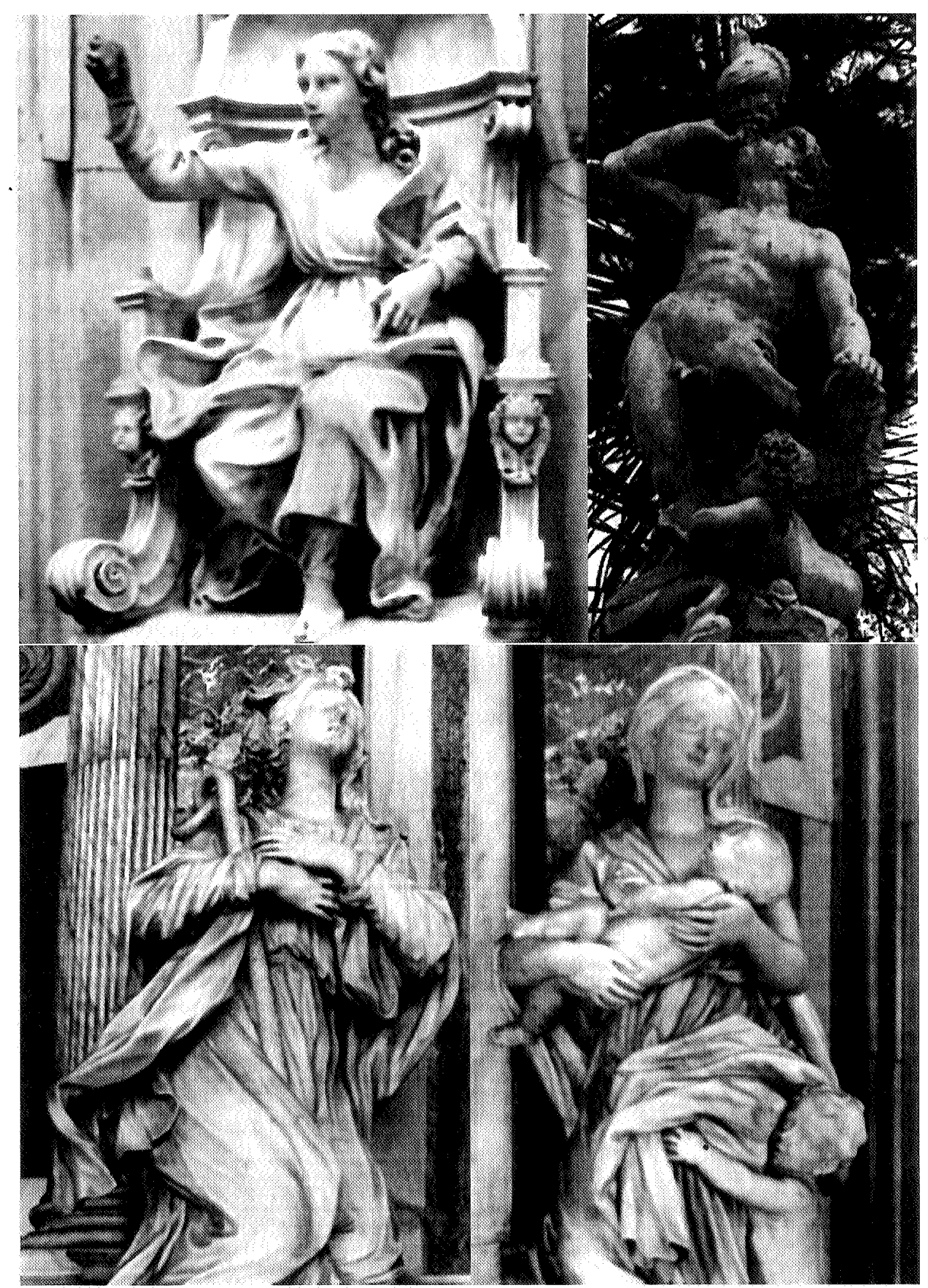

Figuras 27-30. Jacobo Antonio Ponzanelli. Jesús Adolescente. Valencia. Iglesia del Temple. Tritón. Valencia. Jardines. La Esperanza y la Caridad. Génova. Iglesia de la Annunziata. 
El complicado juego de pliegues suaves que contornean las figuras de San Ignacio o de Santo Domingo de Guzmán puede verse en otras obras genovesas de Ponzonelli, como en su bellas figuras de la Esperanza y la Caridad (Figs. 29 y 30) de la Annunziata de Génova.

No puede decirse que este estudio comparativo aclare definitivamente la autoría de los Santos de Mejorada pues hay otros muchos escultores genoveses de estas fechas que trabajan para España y posiblemente también para la poderosa familia genovesa de los Grillo, cuyas obras no conocemos. Por ello únicamente nos permitimos proponer con cierta seguridad que las esculturas de Mejorada son obras genovesas de la segunda mitad del siglo XVII del círculo de los discípulos de Parodi, con claros reflejos de la escultura barroca romana que también aparecen en el napolitano Cosimo Fanzago y en su discípulo Fumo, lo que justifica las dudas habidas en principio en su clasificación ${ }^{55}$.

55 Sobre Frucos, vid. nota 51.- Sobre Ponzanelli: Scultura a Génova, cit. nota 43, pp. 279-280, fig. 318 (Tritón), p. 239, fig. 305, Marcantonio Grille, Figs. 290-291, Esperanza y Caridad. La figura de Jesús adolescente en Valencia, Arte. Pérez Sánchez, A. E.: Tierras de España, Fundación Juan March, 1985, f. 217 , p. 288. 